\title{
XRD and SANS Evaluation of HOPG and Polycrystalline Graphite
}

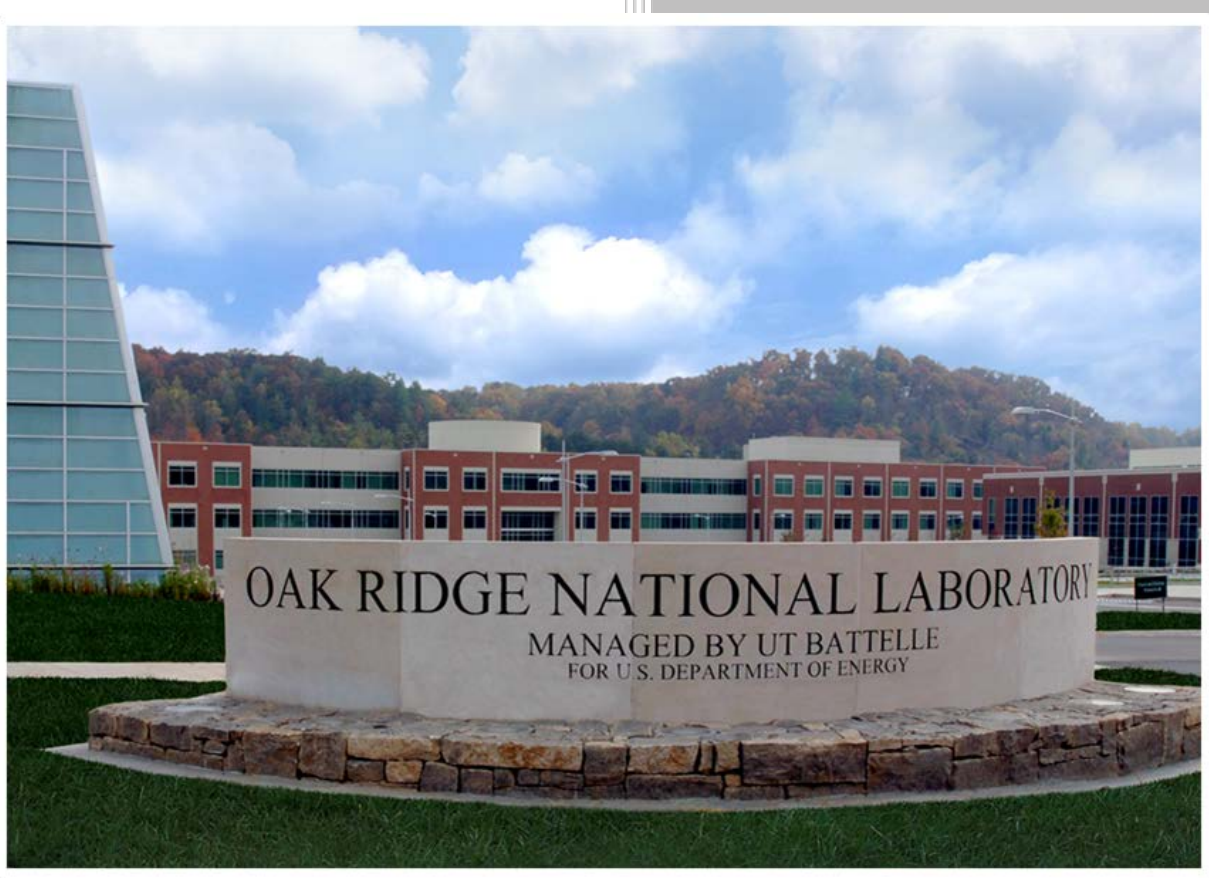

\section{Approved for public release.}

Distribution is unlimited.

Nidia C. Gallego

Cristian I. Contescu

Timothy D. Burchell

June 2018 


\title{
DOCUMENT AVAILABILITY
}

Reports produced after January 1, 1996, are generally available free via US Department of Energy (DOE) SciTech Connect.

\section{Website www.osti.gov}

Reports produced before January 1, 1996, may be purchased by members of the public from the following source:

\author{
National Technical Information Service \\ 5285 Port Royal Road \\ Springfield, VA 22161 \\ Telephone 703-605-6000 (1-800-553-6847) \\ TDD 703-487-4639 \\ Fax 703-605-6900 \\ E-mail info@ntis.gov \\ Website http://classic.ntis.gov/
}

Reports are available to DOE employees, DOE contractors, Energy Technology Data Exchange representatives, and International Nuclear Information System representatives from the following source:

Office of Scientific and Technical Information

PO Box 62

Oak Ridge, TN 37831

Telephone 865-576-8401

Fax 865-576-5728

E-mail reports@osti.gov

Website http://www.osti.gov/contact.html

This report was prepared as an account of work sponsored by an agency of the United States Government. Neither the United States Government nor any agency thereof, nor any of their employees, makes any warranty, express or implied, or assumes any legal liability or responsibility for the accuracy, completeness, or usefulness of any information, apparatus, product, or process disclosed, or represents that its use would not infringe privately owned rights. Reference herein to any specific commercial product, process, or service by trade name, trademark, manufacturer, or otherwise, does not necessarily constitute or imply its endorsement, recommendation, or favoring by the United States Government or any agency thereof. The views and opinions of authors expressed herein do not necessarily state or reflect those of the United States Government or any agency thereof. 
Materials Science and Technology Division

\title{
XRD AND SANS EVALUATION OF HOPG AND POLYCRYSTALLINE GRAPHITE
}

\author{
Nidia C. Gallego \\ Cristian I. Contescu \\ Timothy D. Burchell
}

June 2018

Prepared by

OAK RIDGE NATIONAL LABORATORY

Oak Ridge, TN 37831-6283

managed by

UT-BATTELLE, LLC

for the

US DEPARTMENT OF ENERGY

under contract DE-AC05-00OR22725 



\section{CONTENTS}

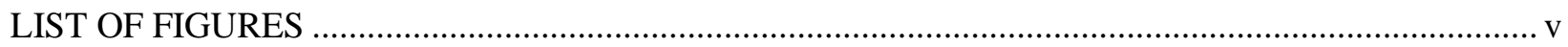

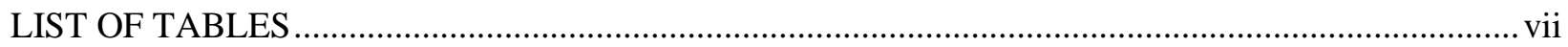

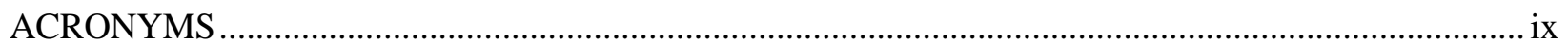

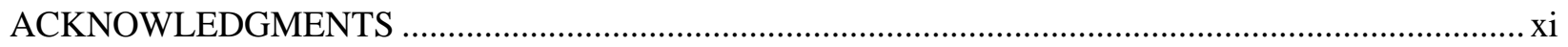

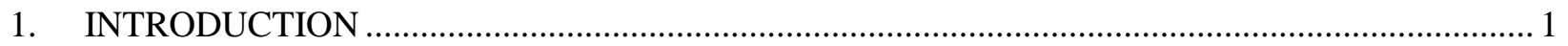

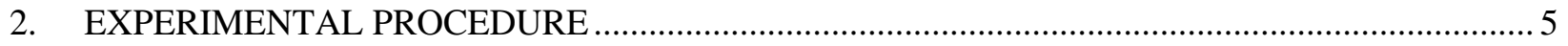

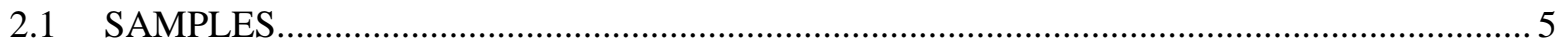

2.1.1 Highly Oriented Pyrolytic Graphite Samples ..................................................... 5

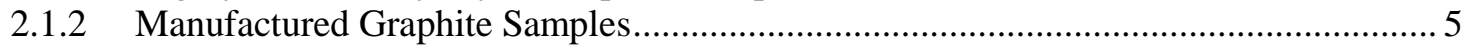

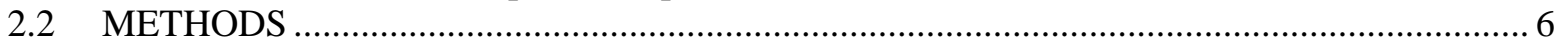

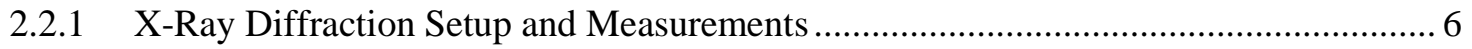

2.2.2 Small-Angle Neutron Scattering Setup and Measurements......................................... 7

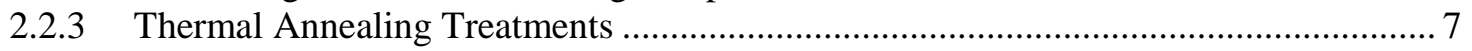

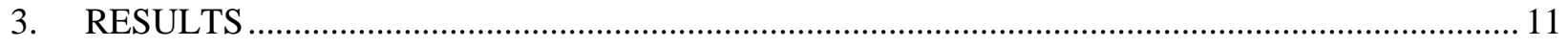

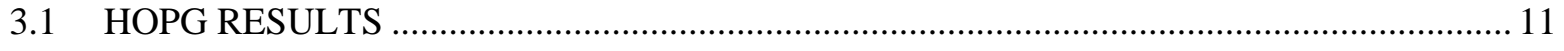

3.1.1 Dimensional Changes and XRD Results ............................................................. 11

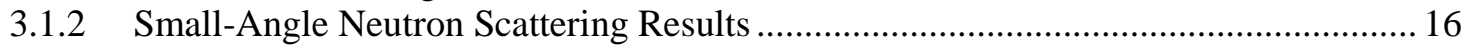

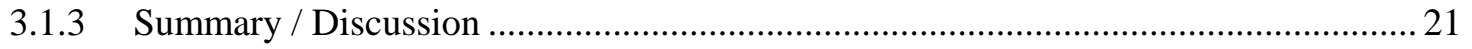

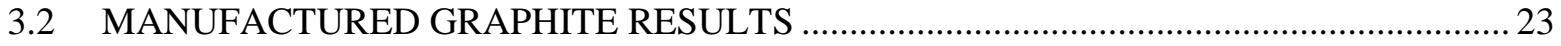

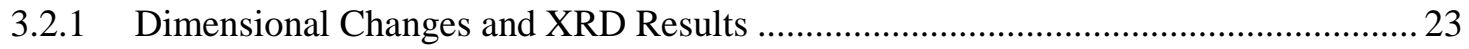

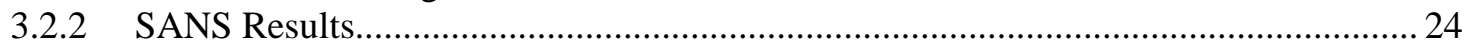

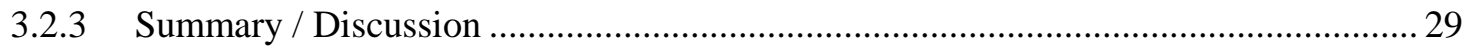

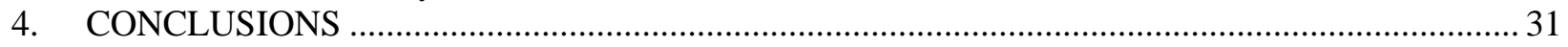

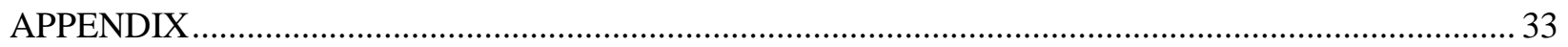





\section{LIST OF FIGURES}

Figure 1. Effect of high-energy neutrons on nuclear graphite: neutron collision generates cascading events that create mobile interstitial atoms and extended vacancies (from ref.

2).

Figure 2. Model of single vacancy / interstitial pair caused by irradiation of graphite (left) and schematic showing the effects of multiple interstitials development and vacancy collapsing on crystallite dimensions (right) (from ref. 3).

Figure 3. Geometry of XRD setup used for (a) HOPG and (b) manufactured graphite samples.................. 8

Figure 4. Geometry of SANS setup used for (a) HOPG and (b) manufactured graphite samples............... 9

Figure 5. Image of (a) graphite crucible used for thermal annealing and (b) HOPG sample before and after annealing showing marked edge.

Figure 6. Effect of irradiation dose on bulk dimensions: (a) thickness (along graphite c-axis), (b) side dimension (along a-axis) and (c) volume.

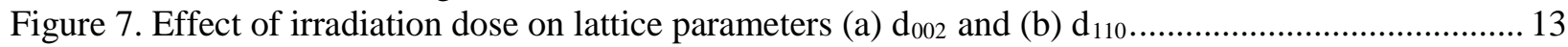

Figure 8. Comparison of results obtained here for dimensional changes of HOPG to those previously reported $\mathrm{d}^{7,8}$ (our results are represented by red circles, overlapped on the original figure)......

Figure 9. Comparison of results obtained for the HOPG from AGC-1 to those previously reported for a near-isotropic graphite (a) lattice parameter $\mathrm{d}_{002}$ and (b) lattice parameter $\mathrm{d}_{110}$ (our results are represented by red circles, overlapped on the original figures) ${ }^{9,10}$............................ 15

Figure 10. Schematic of flat SANS scan and corresponding analysis of the data. .................................... 17

Figure 11. Schematic of side SANS scan and corresponding analysis of the data. ................................. 18

Figure 12. Reduced SANS patterns for unirradiated HOPG corresponding to flat and side (horizontal and vertical) positions.

Figure 13. Reduced SANS patterns (a) flat view and (b) side-horizontal for four HOPG samples after irradiation (solid symbols) and after thermal annealing at $700^{\circ} \mathrm{C}$ (open symbols).

Figure 14. Reduced SANS patterns for side-vertical for four HOPG samples after irradiation (solid symbols) and after thermal anneal at $700^{\circ} \mathrm{C}$ (open symbols).

Figure 15. Schematic demonstration of a possible mechanisms leading to dimensional changes and microcrack development during irradiation: Irradiation may cause separation between slightly misaligned neighboring crystallites, increase of misalignment, and eventually void development between separated crystallites.

Figure 16. Dimensional changes along length and diameter for samples from graphite grades NBG-17, PCEA, IG-110.

Figure 17. Changes in crystalline parameters $\mathrm{d}_{002}$ for samples from graphite grades NBG-17, PCEA, IG-110: (a) uncrept samples, (b) crept samples, and (c) comparison of lattice spacing $\mathrm{d}_{002}$ between manufactured graphite and HOGP......

Figure 18. Unirradiated graphite samples: (a) SANS patterns and (b) corresponding pore size distribution obtained using the spherical pore model. ................................................................ 25

Figure 19. SANS patterns for NBG-17, PCEA, and IG-110 showing the effect of creep and irradiation dose.

Figure 20. Pore size distribution obtained from SANS patterns for irradiated samples of NBG-17, PCEA, and IG-110 graphite.

Figure 21. Comparison of pore size distribution obtained from two methods of porosity analysis: SANS (left panel) and nitrogen adsorption (right panel) applied to the same NBG-17 specimens. 



\section{LIST OF TABLES}

Table 1. List of HOPG and manufactured polycrystalline graphite grades selected for XRD and

SANS measurements.

Table 2. List of HOPG samples sent to ORNL and their irradiation conditions....................................... 5

Table 3. List of selected manufactured graphite samples and their irradiation conditions.......................... 6

Table 4. List of HOPG samples and the various annealing treatments and XRD scans that were performed on each sample.

Table 5. List of HOPG samples and the various annealing treatments and SANS scans that have been applied to samples. 



\section{ACRONYMS}

AGC Advanced Graphite Creep project

ART Advanced Reactor Technologies program

DOE US Department of Energy

dpa displacements per atom

HFIR High Flux Isotope Reactor

HOPG highly oriented pyrolytic graphite

HTGR high-temperature gas-cooled reactors

HTR high-temperature reactor

INL Idaho National Laboratory

PIE post-irradiation examination

SANS small-angle neutron scattering

SAXS small-angle $x$-ray scattering

SNS Spallation Neutron Source

UHP ultra-high purity

USANS ultra small-angle neutron scattering

VHTR very high temperature reactor

XRD X-ray diffraction 



\section{ACKNOWLEDGMENTS}

This work was supported by the U.S. Department of Energy (DOE), Office of Nuclear Energy, Advanced Reactor Technology Program. A portion of this research used resources at the High Flux Isotope Reactor (HFIR) and the Spallation Neutron Source (SNS), both DOE Office of Science User Facilities operated by the Oak Ridge National Laboratory (ORNL).

The authors are grateful to Lilin He (ORNL) for the help with data collection and use of equipment at the Small Angle Neutron Scattering beam lines at HFIR and SNS, and to Melanie Kirkham (ORNL) for the help with data collection and use of equipment for x-ray diffraction. The authors are also grateful to William Windes (Idaho National Laboratory) for his consistent support and encouragement of this work and for excellent feedback during the preparation of this report. 



\section{INTRODUCTION}

As the primary construction material used in gas-cooled reactor cores, either of high-temperature (HTR) or very high-temperature (VHTR) design, nuclear graphite must be well characterized and variations in its properties upon high-energy neutron irradiation must be known, understood, and predicted as accurately as possible before a reactor is built and operational. However, even after more than 70 years of operation of graphite-moderated reactors and intense research on graphite's behavior in an extreme environment created by high temperatures, irradiation, mechanical stress, and chemically reactive (oxidizing) gaseous environment, questions still remain. The main concern is related to the stability of graphite components over the reactor lifetime. There are many grades of graphite, each with its own precursors, manufacturing methods, and microstructures, but what is true for almost all grades is that irradiation induces dimensional shrinkage up to a turnaround dose level, after which continued irradiation causes swelling back to (or even beyond) the initial dimensions. These changes are accompanied by variations in mechanical, thermal, and electrical properties which need to be accommodated in the reactor design phase. The problem is that the properties of each graphite grade, engineered by manufacturers to predetermined requirements, may show response curves with very different rates, depending on the irradiation conditions. Although these changes follow a common scenario, the unique properties of each grade are not known a priori and must be determined by lengthy and costly irradiation campaigns. ${ }^{1}$
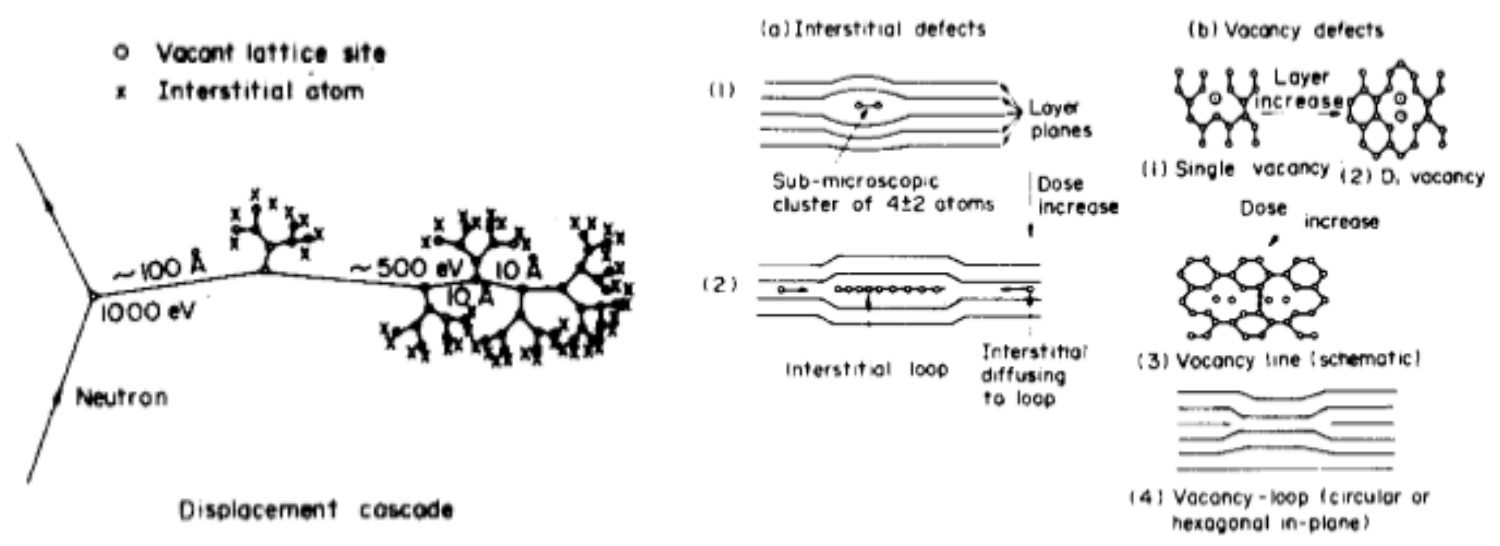

Figure 1. Effect of high-energy neutrons on nuclear graphite: neutron collision generates cascading events that create mobile interstitial atoms and extended vacancies (from ref. 2).

Understanding the basic processes that occur under energetic neutron irradiation is necessary for the development of predictive tools that may be used by designers to foresee dimensional changes and other physical properties under different temperatures and various neutron spectrums. The generally accepted view is that energetic neutrons colliding with carbon atom nuclei initiate a chain of cascading events that displace carbon atoms from the lattice position and leave behind vacant lattice sites (Figure 1). ${ }^{2}$ Displaced (interstitial) atoms may diffuse, coalesce, or aggregate between the graphite basal planes, causing crystal expansion in the c-direction. If the crystal volume remains constant, a simultaneous shrinkage is expected in the a-direction (Figure 2). ${ }^{3}$

\footnotetext{
${ }^{1}$ Irradiation damage in graphite due to fast neutrons in fission and fusion systems, IAEA-TECDOC-1154, International Atomic Energy Agency (2000); http://www-pub.iaea.org/MTCD/publications/PDF/te_1154_prn.pdf

${ }^{2}$ B. T. Kelly, "Graphite - The most fascinating nuclear material," Carbon 20 (1982) 3-11.

${ }^{3}$ T. D. Burchell, J. P. Strizak, “The effect of neutron irradiation on the fracture toughness in graphite,” Nuclear Engineering and Design 271 (2014) 262-269.
} 


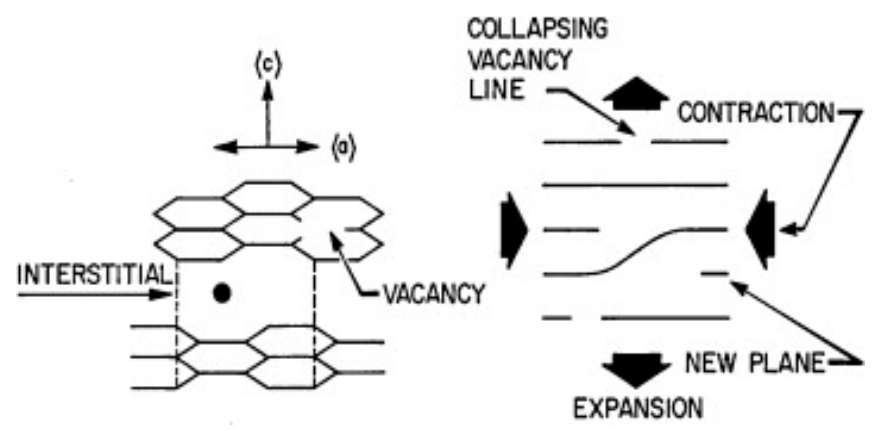

Figure 2. Model of single vacancy / interstitial pair caused by irradiation of graphite (left) and schematic showing the effects of multiple interstitials development and vacancy collapsing on crystallite dimensions (right) (from ref. 3).

A complicating factor is that local differences in received dose and temperature induce internal differential stresses in graphite components. These stresses may be significant and could cause premature failure of graphite if it were not for neutron-irradiation-induced creep strain. ${ }^{4}$ The experimental irradiation-induced creep strain is measured by comparing dimensional changes of two identical specimens in which one is irradiated under external stress and the other is unstressed, with all other conditions (dose, temperature, orientation) being the same. The irradiation creep strain is believed to reflect partial annealing of interstitial clusters and release of dislocation lines. Following a mechanism still under investigation ${ }^{5}$ but which clearly depends on temperature, irradiation fluence, and internal stress, the graphite crystal seems to flow through basal plane and slip into a less strained condition.

The goal of understanding and modeling the creep mechanism of nuclear graphite components during operation under load at high temperatures and high fluences of fast neutrons remains elusive even after seven decades of experience with graphite-moderated nuclear reactors. Graphite components bear the load in the reactor, especially those at the base of the structure; hence, an accurate understanding of graphite dimensional behavior is needed to ensure that the control rods maintain free passage through the fuel elements and the reactor can be controlled for safe operation. Some of the graphite components are not replaceable, so their irradiation-induced deformation must be predicted and accounted for from the design phase through many years of operation until final disassembly at the reactor's end of life. This task is made difficult by the fact that the information accumulated over many years of observation and research remains scattered, the variables and operation conditions are too diverse, and the knowledge gaps in the data are too many and hard to bridge.

The above explains why research on graphite creep under irradiation continues with intensity in several countries. A vast irradiation experiment known as the Advanced Graphite Creep (AGC) project is in progress in the USA, conducted under the Advanced Reactor Technologies (ART) program of the US Department of Energy (DOE). The goal is to characterize, compare, and understand the effects of irradiation creep on a large selection of graphite grades available from different vendors, sourced from different precursors, and manufactured by different methods. When completed, this experiment will provide creep data over the entire reactor design envelope, allowing an informed selection of commercial graphite grades that might be used in high-temperature gas-cooled reactors (HTGRs). In the first phase of the experiment, the AGC-1 capsule provided graphite samples irradiated at doses of 2.8-6.9 displacements per atom (dpa) and temperatures of $470-716^{\circ} \mathrm{C}$. Specimens were irradiated in parallel using both unstressed (uncrept) and stressed (crept) conditions, with three levels of applied stress (roughly

\footnotetext{
${ }^{4}$ T. D. Burchell, “Irradiation induced creep behavior of H-451 graphite,” J. Nuclear Materials 381 (2008) 46-54.

${ }^{5}$ T. D. Burchell, "Carbon Materials for Advanced Technologies,” in T D Burchell (Ed.), Elsevier Sci. (Publ.) 1999, p. 429, Chapter 13.
} 
13.8, 17.3, and 20.7 MPa). Analysis of the results provided data on the effect of neutron irradiation on dimensions and key physical properties, including graphite creep rate.

At the same time, the irradiated specimens from AGC-1 capsule constitute a high-value library of graphite grades from various vendors and with various properties, all irradiated under controlled conditions. Taking advantage of that, a basic research project was initiated at ORNL with the goal of revealing and understanding the microstructural changes induced by the irradiation creep mechanism. After traditional dimensional changes during post-irradiation examination (PIE) were noted, several irradiated specimens were selected for further characterization using x-ray diffraction (XRD) and small-angle neutron scattering (SANS). Some irradiated specimens were further annealed at various temperatures, and their structures were again characterized using the same techniques. The selection included several polycrystalline nuclear graphite grades from major graphite vendors along with highly oriented pyrolytic graphite (HOPG). This report summarizes the results obtained from the study of irradiated (with and without stress) and thermally annealed graphite materials as compared with their unirradiated counterparts. Irradiation was performed in the Advanced Test Reactor (ATR) at Idaho National Laboratory (INL) at approximately $700^{\circ} \mathrm{C}$.

Going from simple to complex, the HOPG material was examined first. This material is generally considered a good model of (almost) perfect graphite so that observing the effects of irradiation and annealing would make it possible to extract more fundamental information about the changes occurring along the main crystal directions. In a second phase the investigation was extended to polycrystalline graphite grades. Three graphite grades considered as main candidates for HTGR designs were selected for detailed study. They were chosen with the aim of exploring a large combination of precursors, grain sizes, and manufacturing methods, thus reflecting the currently offered commercially available graphite grades (Table 1).

The report is organized by materials and by experimental methods. The results obtained with irradiated and annealed HOPG will be presented first and compared with data available in the literature. The good agreement between current results on HOPG and benchmark literature results demonstrates the accuracy of the procedures used. Moreover, the combined analysis of dimensional, XRD, and SANS data on (almost) perfectly structured HOPG led to interesting results that are presented below. The same methods were applied to polycrystalline graphite irradiated at various doses and temperatures. The goal was to compare specimens irradiated at similar fluence and temperature under crept and uncrept conditions. The results are discussed separately for HOPG and polycrystalline graphites. 
Table 1. List of HOPG and manufactured polycrystalline graphite grades selected for XRD and SANS measurements.

\begin{tabular}{|c|c|c|c|c|}
\hline \multicolumn{2}{|c|}{ Graphite } & Source & Process Details & Further studies \\
\hline \multicolumn{2}{|r|}{ HOPG } & GE Advanced Ceramics & $\begin{array}{c}\text { Pyrolytic Graphite } \\
\text { Monochromator - Grade ZYB }\end{array}$ & $\begin{array}{l}\text { Dimensions XRD, SANS, } \\
\text { annealing }\end{array}$ \\
\hline \multirow{6}{*}{ 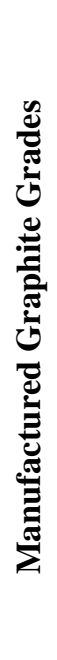 } & NBG-17 & $\begin{array}{c}\text { SGL Carbon } \\
\text { (Germany/France) }\end{array}$ & $\begin{array}{l}\text { Pitch coke, vibrationally molded. } \\
\text { Medium grain }\end{array}$ & $\begin{array}{l}\text { Dimensions XRD, SANS, } \\
\text { annealing, } \mathrm{N}_{2} \text { adsorption }\end{array}$ \\
\hline & PCEA & $\begin{array}{l}\text { GrafTech International } \\
\text { (USA) }\end{array}$ & $\begin{array}{l}\text { Petroleum coke, extruded. } \\
\text { Medium grain }\end{array}$ & $\begin{array}{l}\text { Dimensions XRD, SANS, } \\
\text { annealing, } \mathrm{N}_{2} \text { adsorption }\end{array}$ \\
\hline & IG-110 & $\begin{array}{l}\text { Toyo Tanso } \\
\text { (Japan) }\end{array}$ & $\begin{array}{c}\text { Petroleum coke, isostatically } \\
\text { molded. } \\
\text { Fine grain }\end{array}$ & $\begin{array}{l}\text { Dimensions XRD, SANS, } \\
\text { annealing, } \mathrm{N}_{2} \text { adsorption }\end{array}$ \\
\hline & NBG-18 & $\begin{array}{c}\text { SGL Carbon } \\
\text { (Germany/France) }\end{array}$ & $\begin{array}{l}\text { Pitch coke, vibrationally molded. } \\
\text { Medium grain }\end{array}$ & Dimensions \\
\hline & IG-430 & $\begin{array}{l}\text { Toyo Tanso } \\
\text { (Japan) }\end{array}$ & $\begin{array}{c}\text { Pitch coke, isostatically molded. } \\
\text { Fine grain }\end{array}$ & Dimensions \\
\hline & $\mathrm{H}-451$ & $\begin{array}{l}\text { SGL Carbon } \\
\text { (USA) }\end{array}$ & $\begin{array}{l}\text { Petroleum coke, extruded. } \\
\text { Medium grain }\end{array}$ & Dimensions \\
\hline
\end{tabular}




\section{EXPERIMENTAL PROCEDURE}

\subsection{SAMPLES}

\subsubsection{Highly Oriented Pyrolytic Graphite Samples}

The Highly Oriented Pyrolytic Graphite (HOPG) samples used for the irradiation studies were grade ZYB Pyrolytic Graphite Monochromator, acquired from GE Advanced Ceramics (now Momentive) in Strongsville, $\mathrm{OH} 44149$. They had nominal dimension of $5 \mathrm{~mm} \times 5 \mathrm{~mm} \times 2 \mathrm{~mm}$.

A set of 16 HOPG specimens were irradiated as part of the AGC-1 campaign. Eight of the HOPG samples (one-half of the set) were sent to ORNL for evaluation. The other half was kept at INL for analysis. The samples sent to ORNL received doses varying from 3.09 up to $6.82 \mathrm{dpa}$ at irradiation temperatures from 511 up to $750^{\circ} \mathrm{C}$. Table 2 lists a summary of the samples along with their irradiation conditions (temperature and dose), per Document ID ECAR-1943. ${ }^{6}$

Table 2. List of HOPG samples sent to ORNL and their irradiation conditions.

\begin{tabular}{|c|c|c|}
\hline Sample & $\left.\mathbf{T}_{\text {irr }}{ }^{\circ} \mathbf{C}\right)$ & Dose (dpa) \\
\hline HOPG-unirradiated & - & - \\
\hline CPB1 & 619 & 3.41 \\
\hline CPB21 & 678 & 5.06 \\
\hline CPB51 & 744 & 6.49 \\
\hline CPB71 & 751 & 6.82 \\
\hline CPB101 & 726 & 6.62 \\
\hline CPB121 & 690 & 6.01 \\
\hline CPB141 & 622 & 4.88 \\
\hline CPB161 & 511 & 3.09 \\
\hline
\end{tabular}

\subsubsection{Manufactured Graphite Samples}

In addition to the HOPG samples, a selected set of manufactured graphite samples were selected for XRD and SANS studies. For this purpose, 24 irradiated samples from the ACG-1 capsule were selected after all other PIE required analysis was completed, including the flexural tests. The 24 samples represent 12 pairs (crept/uncrept) from six main graphite grades, at two levels (low/high) of irradiation dose. Six additional unirradiated graphite samples, representing each one of the graphite grades, were also selected. For the analysis, discs approximately $2 \mathrm{~mm}$ in thickness were machined from the samples.

Table 3 lists a summary of the samples along with their irradiation conditions (temperature, dose, and load), per Document ID ECAR-1943.

${ }^{6}$ Document ID: ECAR-1943; Project No. 23747, Rev. 0 (Idaho National Laboratory). 
Table 3. List of selected manufactured graphite samples and their irradiation conditions.

\begin{tabular}{|c|c|c|c|c|c|}
\hline $\begin{array}{l}\text { Graphite } \\
\text { Grade }\end{array}$ & $\begin{array}{l}\text { Specimen ID } \\
\text { / Number }\end{array}$ & $\begin{array}{c}\text { Irradiation } \\
\text { Fluence } \\
\text { (dpa) }\end{array}$ & $\begin{array}{c}\text { Irradiation } \\
\text { Temperature } \\
\left({ }^{\circ} \mathrm{C}\right)\end{array}$ & $\begin{array}{c}\text { Irradiation } \\
\text { Power } \\
\text { Weighted } \\
\text { Load (lbf) }\end{array}$ & $\begin{array}{c}\text { Irradiation } \\
\text { Load (MPa) }\end{array}$ \\
\hline \multirow{5}{*}{ NBG-17 } & AW1-03 & 3.47 & 589 & -377 & 13.2 \\
\hline & AW2-03 & 2.87 & 468 & 0 & 0 \\
\hline & AW10-03 & 6 & 670 & -558 & 17.3 \\
\hline & AW12-03 & 5.43 & 594 & 0 & 0 \\
\hline & NBG-17-A & \multicolumn{4}{|c|}{ unirradiated } \\
\hline \multirow{5}{*}{ PCEA } & DW1-03 & 4.36 & 606 & -377 & 13.2 \\
\hline & DW2-03 & 3.91 & 533 & 0 & 0 \\
\hline & DW5-02 & 5.66 & 669 & -565 & 19.8 \\
\hline & DW6-01 & 5.02 & 585 & 0 & 0 \\
\hline & DA7-7 & \multicolumn{4}{|c|}{ unirradiated } \\
\hline \multirow{5}{*}{ IG-110 } & EW2-02 & 4.75 & 621 & -377 & 13.2 \\
\hline & EW2-03 & 4.36 & 562 & 0 & 0 \\
\hline & EW4-02 & 6.54 & 693 & -558 & 19.6 \\
\hline & EW5-02 & 6.18 & 653 & 0 & 0 \\
\hline & E5-3-1 & \multicolumn{4}{|c|}{ unirradiated } \\
\hline \multirow{5}{*}{ NBG-18 } & BW1-02 & 3.41 & 504 & 0 & 0 \\
\hline & BW5-03 & 5.63 & 617 & 0 & 0 \\
\hline & BW12-02 & 3.93 & 597 & -171 & 6.0 \\
\hline & BW3-03 & 6.13 & 678 & -256 & 9.0 \\
\hline & BB3-3-1 & \multicolumn{4}{|c|}{ unirradiated } \\
\hline \multirow{5}{*}{ IG-430 } & FW4-01 & 2.78 & 472 & 0 & 0 \\
\hline & FW7-01 & 6.28 & 670 & 0 & 0 \\
\hline & FW12-01 & 3.37 & 593 & -215 & 7.6 \\
\hline & FW4-03 & 6.59 & 707 & -256 & 9.0 \\
\hline & F9-3-1 & \multicolumn{4}{|c|}{ unirradiated } \\
\hline \multirow{5}{*}{ H-451 } & CW8-02 & 6.7 & 674 & 0 & 0 \\
\hline & CW10-02 & 6.66 & 681 & 0 & 0 \\
\hline & CW7-03 & 5.44 & 649 & -171 & 6.0 \\
\hline & CW9-03 & 6.81 & 712 & -256 & 9.0 \\
\hline & C9-3 & \multicolumn{4}{|c|}{ unirradiated } \\
\hline
\end{tabular}

\subsection{METHODS}

\subsubsection{X-Ray Diffraction Setup and Measurements}

Due to the anisotropic nature of the HOPG samples, each specimen requires at least two scans in order to fully characterize the crystalline parameters, such as $\mathrm{d}_{002}$ spacing, $\mathrm{L}_{\mathrm{c}}$ and $\mathrm{L}_{\mathrm{a}}$. The "surface" scans provide information on planes along the c-axis, namely, the (002) planes and their reflections (i.e., (004) and (006)). The "edge" scans provide information on planes along the a-axis, namely, the (100) and (110). The manufactured graphite samples consist of a (nearly) random distribution of crystallites, and therefore a single scan is sufficient to determine crystalline parameters along both the c- and a-axes. See Figure 3 for a schematic representation of the setup and the scans performed. XRD analysis was performed using a 
PANAlytical instrument equipped with $\mathrm{Cu}-\mathrm{k} \alpha$ radiation, wavelength $\lambda=0.154056 \mathrm{~nm}$, and diffraction angle $2 \theta$ from 10 to $140^{\circ}$.

\subsubsection{Small-Angle Neutron Scattering Setup and Measurements}

In the SANS instrument a graphite specimen is exposed to a focalized flux of neutrons of controlled wavelength. The neutrons penetrating the material are elastically scattered by nonhomogeneitiesinternal phases having a different density from the surrounding matrix that contains them. In graphite, scattering occurs on cracks, voids, pores etc., where the continuous distribution of carbon density is interrupted by defects. Because the interaction of neutrons with atoms is weak, the signals from scattered neutrons are weaker than in $\mathrm{x}$-ray scattering, and measurements require more time.

Following the method also used for XRD measurements, neutron scattering was performed on the surface and edge positions of HOPG crystals ( $5 \mathrm{~mm} \times 5 \mathrm{~mm} \times 2 \mathrm{~mm}$ ) and on only a single position for the discs machined from polycrystalline manufactured graphite grades. Figure 4 shows a schematic representation of the setup and the scans performed on the various samples. In this figure, the angle $\theta$ between the incident and the scattered neutron beam defines the scattering vector $Q$ in reciprocal space. The latter is inversely proportional to the characteristic length size $D$ (or radius of gyration) of scattering objects. Varying the scattering angle (or the magnitude of the scattering vector) allows multiscale measurements of objects ranging in size from sub-nanometers (SANS) to microns (USANS). The range is determined mainly by the geometry of each neutron scattering instrument and the wavelength of the impinging neutron flux.

SANS measurements were performed using two instruments:

- Beamline 6 (EQ-SANS) at the Spallation Neutron Source (SNS) at ORNL. This instrument uses a pulsed neutron source, with the option of selecting two wavelength bands (6-9 $\AA$ and 2-6 $\AA$ ). The sample-to-detector distance was $1.3 \mathrm{~m}$. The neutron beam size was $2 \mathrm{~mm}$ for both the surface and edge positions of the HOPG specimens.

- CG-2 (General Purpose SANS) at the High Flux Isotope Reactor (HFIR) at ORNL. This instrument uses a continuous source of neutrons with fixed wavelength (4.75 $\AA$ ). Two sample-to-detector distances were used ( $1 \mathrm{~m}$ and $18.5 \mathrm{~m}$ ) in order to cover a broad range of momentum transfer vectors. The neutron beam size was $2 \mathrm{~mm}$ for "side" positions of HOPG specimens and $4 \mathrm{~mm}$ for "flat" positions of HOPG and all polycrystalline manufactured graphites.

Due to limited funding as well as limited access to neutron beam time, SANS characterization was only performed on three graphite grades of crept and uncrept irradiated specimens (NBG-17, PCEA, and IG110).

\subsubsection{Thermal Annealing Treatments}

After initial characterization, irradiated HOPG samples were thermally annealed. The idea is that thermal treatments may induce some recovery of the damage originally induced by neutron irradiation. For the thermal annealing cycles, specimens were removed from marked containers and photographed. Specimens were then loaded into a graphite crucible with four small holes to contain the samples. A mark next to each hole helped maintain the identity of the samples (Figure 5a). Thermal treatment was carried out in an Astro furnace; the furnace was evacuated and backfilled twice before starting thermal treatment. The chamber purge ran $500 \mathrm{~cm}^{3} /$ minute of ultra-high purity (UHP) argon. The samples were photographed again after treatment (Figure 5b). 


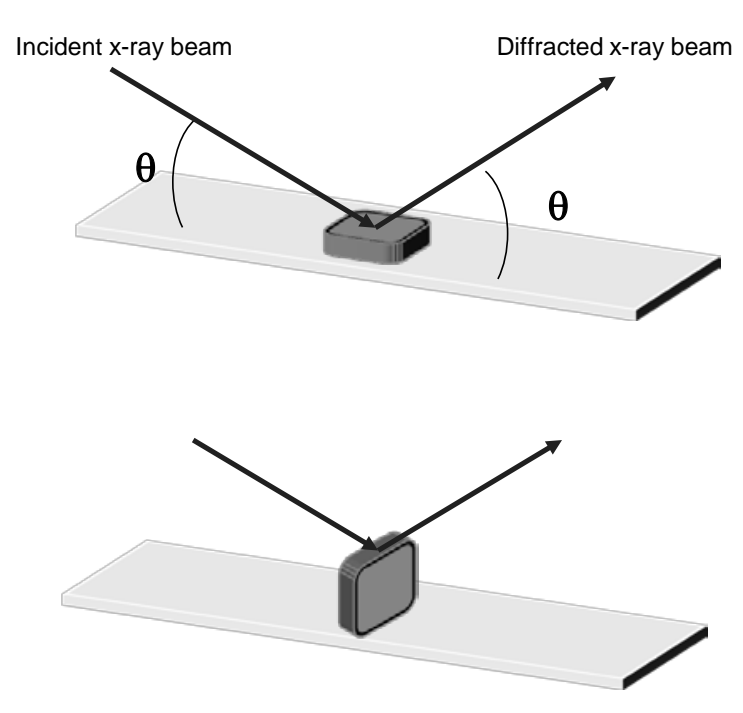

XRD was performed using PANAlytical machine using Cu-ka radiation, $\lambda$, of $0.154056 \mathrm{~nm}, 2 \Theta$ range of 10 to $140^{\circ}$
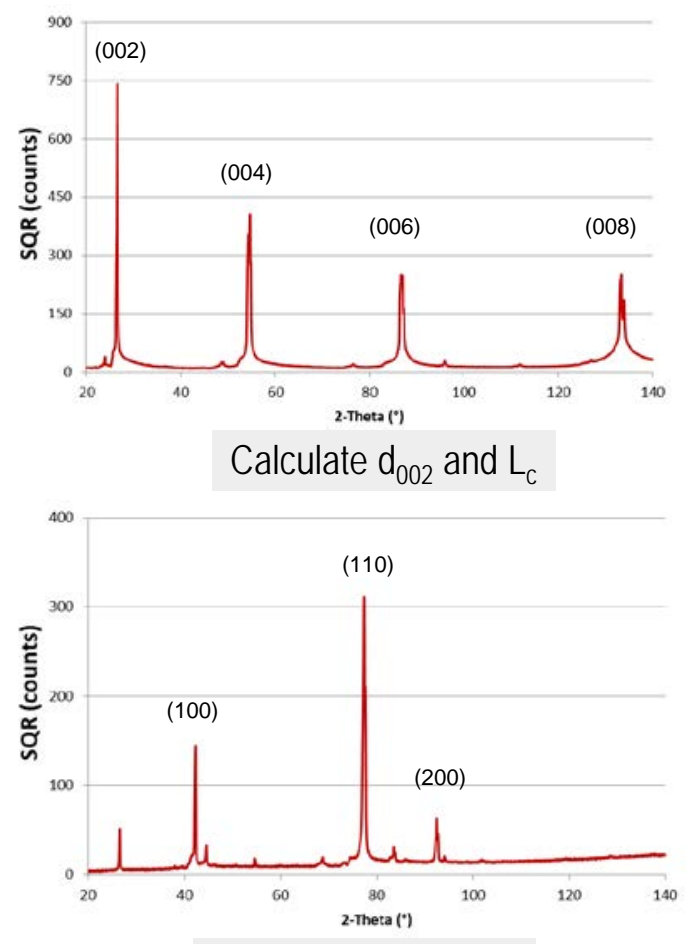

Calculate $\mathrm{d}_{110}$ and $\mathrm{L}_{\mathrm{a}}$

(a)
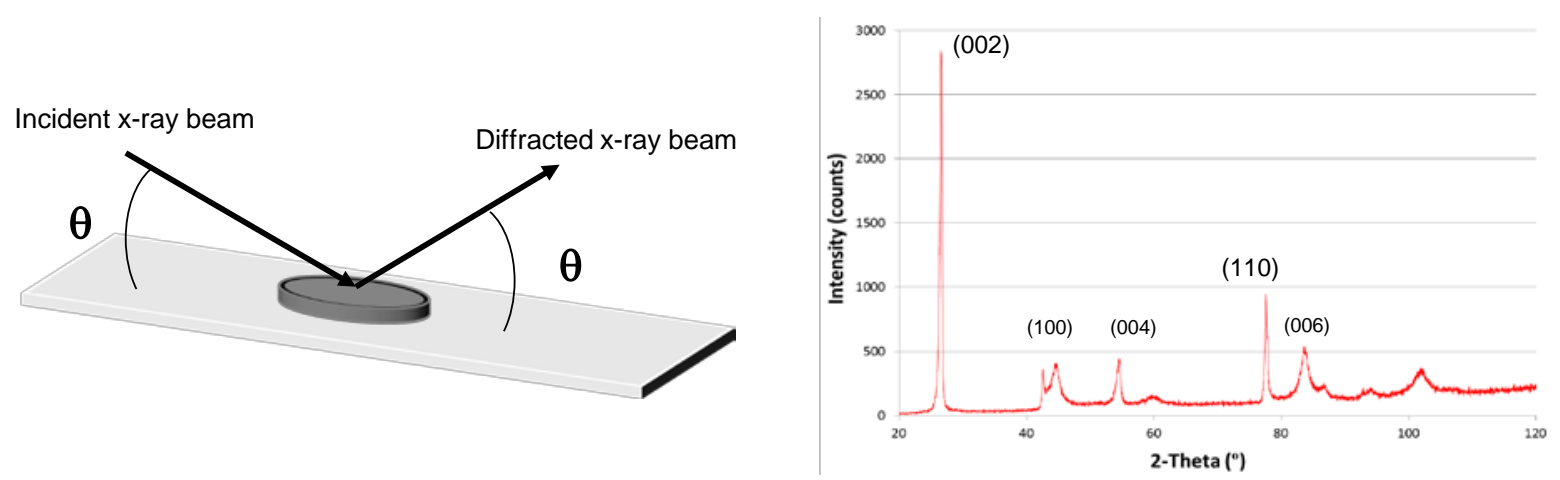

(b)

Figure 3. Geometry of XRD setup used for (a) HOPG and (b) manufactured graphite samples. 


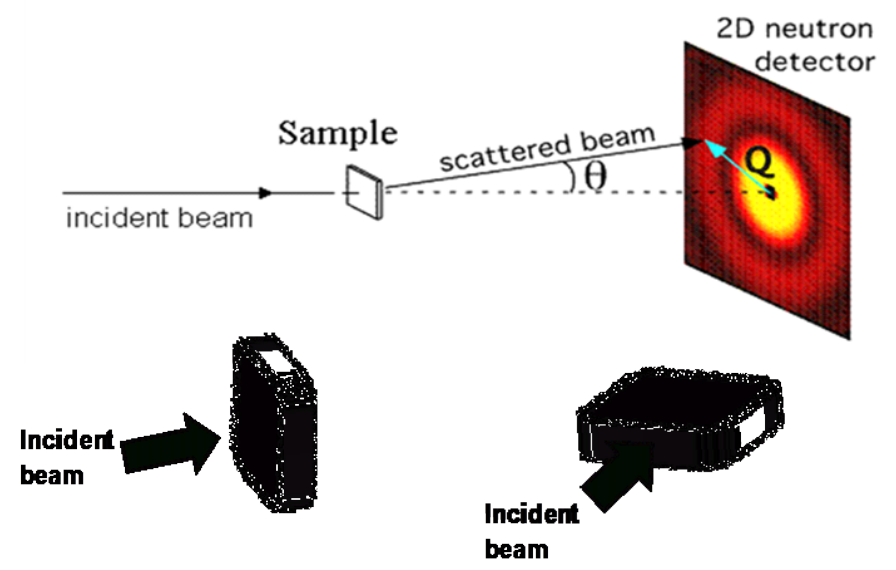

(a)
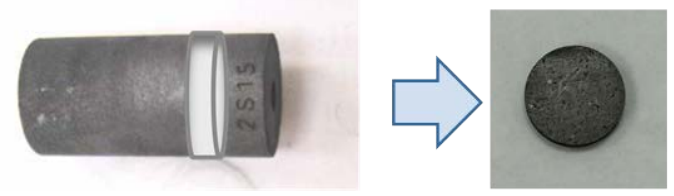

Incident

Neutron beam

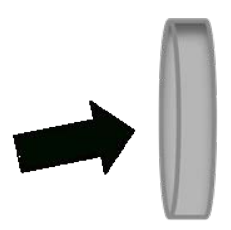

(b)

Figure 4. Geometry of SANS setup used for (a) HOPG and (b) manufactured graphite samples. 


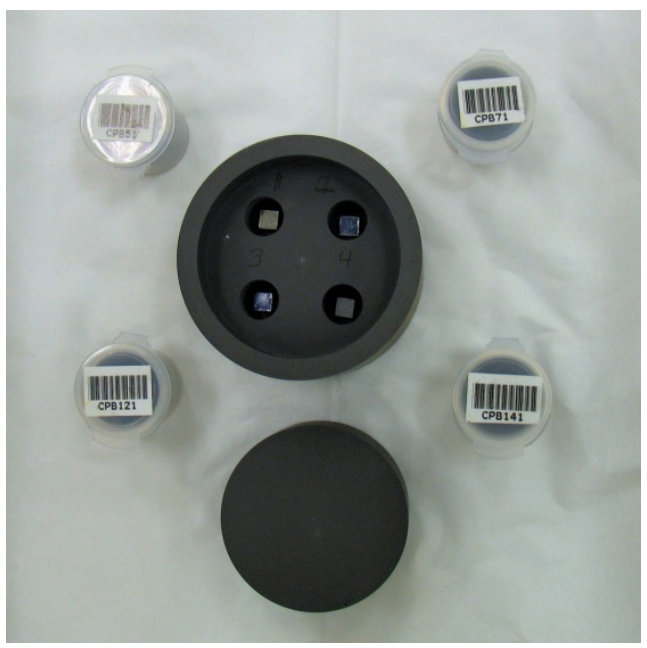

(a)

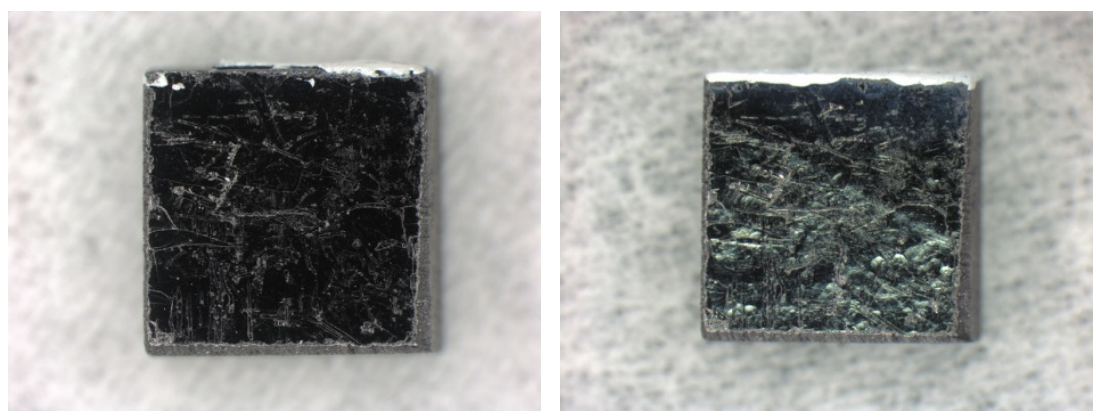

(b)

Figure 5. Image of (a) graphite crucible used for thermal annealing and (b) HOPG sample before and after annealing showing marked edge. 


\section{RESULTS}

\subsection{HOPG RESULTS}

\subsubsection{Dimensional Changes and XRD Results}

Post-irradiation examination (PIE) was carried out and dimensional analysis was performed on all samples, along with XRD analysis of post-irradiated samples. Stepwise annealing to 700, 900, and $1200^{\circ} \mathrm{C}$ was applied to selected samples. Dimensional analysis and x-ray analysis were performed after each annealing cycle. Table 4 summarizes the samples and various annealing treatments that were applied. All eight irradiated specimens were characterized after irradiation and after annealing to $700^{\circ} \mathrm{C}$, but only four specimens were annealed to $900^{\circ} \mathrm{C}$ and $1200^{\circ} \mathrm{C}$, with subsequent XRD analysis.

Table 4. List of HOPG samples and the various annealing treatments and XRD scans that were performed on each sample.

\begin{tabular}{|c|c|c|c|c|c|c|}
\hline & \multicolumn{2}{|l|}{} & $\begin{array}{c}\text { After } \\
\text { Irradiation }\end{array}$ & $\begin{array}{c}\mathbf{1}^{\text {st }} \text { Anneal } \\
\mathbf{7 0 0}^{\circ} \mathbf{C}\end{array}$ & $\begin{array}{c}\mathbf{2}^{\text {nd }} \text { Anneal } \\
\mathbf{9 0 0} \mathbf{C}\end{array}$ & $\begin{array}{c}3^{\text {rd }} \text { Anneal } \\
\mathbf{1 2 0 0}^{\circ} \mathbf{C}\end{array}$ \\
\hline Sample & $\begin{array}{c}\mathrm{T}_{\text {irr }} \\
\left({ }^{\circ} \mathrm{C}\right)\end{array}$ & $\begin{array}{c}\text { Dose } \\
(\mathrm{dpa})\end{array}$ & $\begin{array}{c}\text { Dimensions } \\
\text { x-ray scan }\end{array}$ & $\begin{array}{c}\text { Dimensions } \\
\text { x-ray scan }\end{array}$ & $\begin{array}{c}\text { Dimensions } \\
\text { x-ray scan }\end{array}$ & $\begin{array}{c}\text { Dimensions } \\
\text { x-ray scan }\end{array}$ \\
\hline $\begin{array}{c}\text { HOPG- } \\
\text { unirradiated }\end{array}$ & - & - & $\checkmark$ & - & - & - \\
\hline CPB1 & 619 & 3.41 & $\checkmark$ & $\checkmark$ & $\checkmark$ & $\checkmark$ \\
\hline CPB21 & 678 & 5.06 & $\checkmark$ & $\checkmark$ & $\checkmark$ & $\checkmark$ \\
\hline CPB101 & 726 & 6.62 & $\checkmark$ & $\checkmark$ & $\checkmark$ & $\checkmark$ \\
\hline CPB161 & 511 & 3.09 & $\checkmark$ & $\checkmark$ & $\checkmark$ & $\checkmark$ \\
\hline CPB51 & 744 & 6.49 & $\checkmark$ & $\checkmark$ & n/a & n/a \\
\hline CPB71 & 751 & 6.82 & $\checkmark$ & $\checkmark$ & n/a & n/a \\
\hline CPB121 & 690 & 6.01 & $\checkmark$ & $\checkmark$ & n/a & n/a \\
\hline CPB141 & 622 & 4.88 & $\checkmark$ & $\checkmark$ & n/a & n/a \\
\hline
\end{tabular}

Irradiation did not change the weight of HOPG specimens (as expected) but did change their dimensions and the density. The effects of dose on the bulk dimensional changes of HOPG samples after irradiation and after stepwise annealing at 700,900 , and $1200^{\circ} \mathrm{C}$ are shown in Figure 6 . The results from the PIE dimensional analysis showed, as expected, an increase in the sample thickness (dimension aligned with the crystal c-axis) and a decrease in the sample width (dimension aligned with the crystal a-axis) after irradiation. This agrees with the model for irradiation damage in graphite (Figure 2) in which irradiation damage causes expansion of the c-axis and shrinkage of the a-axis. The net volume change was positive for all specimens. It should be noted that if the HOPG samples were a perfect analog of the graphite single crystal, there would be no net volume change accompanying irradiation-induced dimensional changes. However, the fact that a slight swelling is observed in all cases indicates that a slight misalignment of the crystals in the HOPG samples develops upon irradiation. Thermal annealing in most cases appears to help recover some of the damage induced during irradiation. Some of the variability in the results could be attributed to the not-so-smooth surfaces on the HOPG samples, as shown in Figure 5b. 


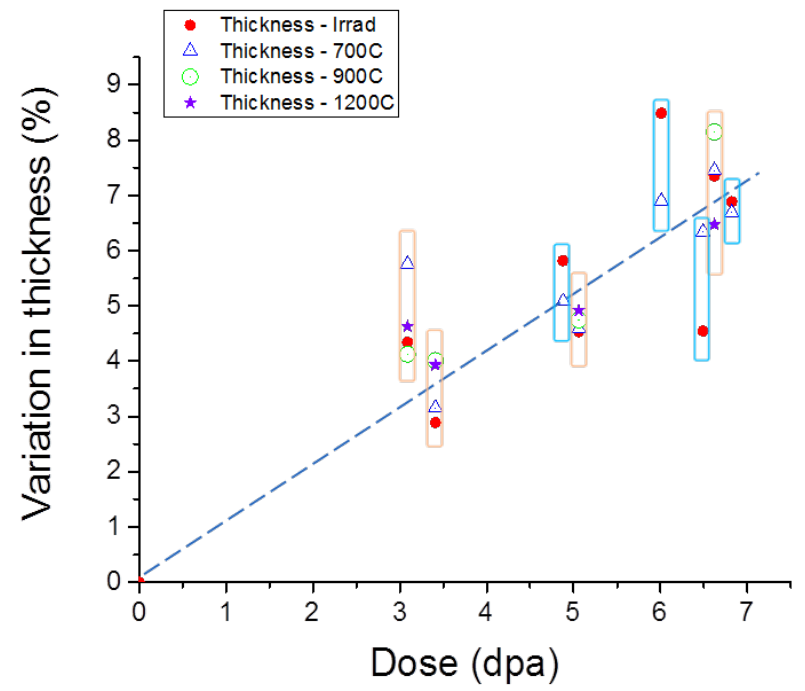

(a)

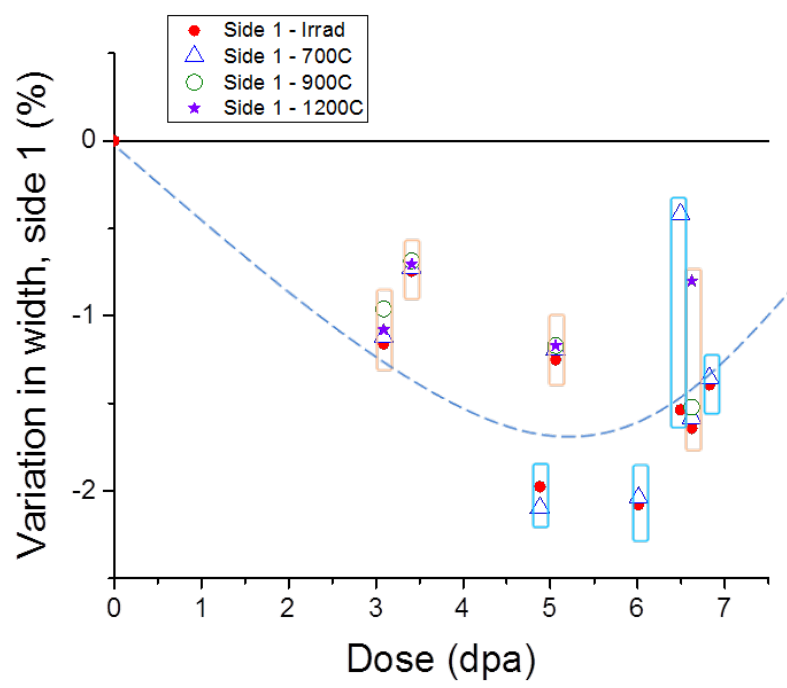

(b)

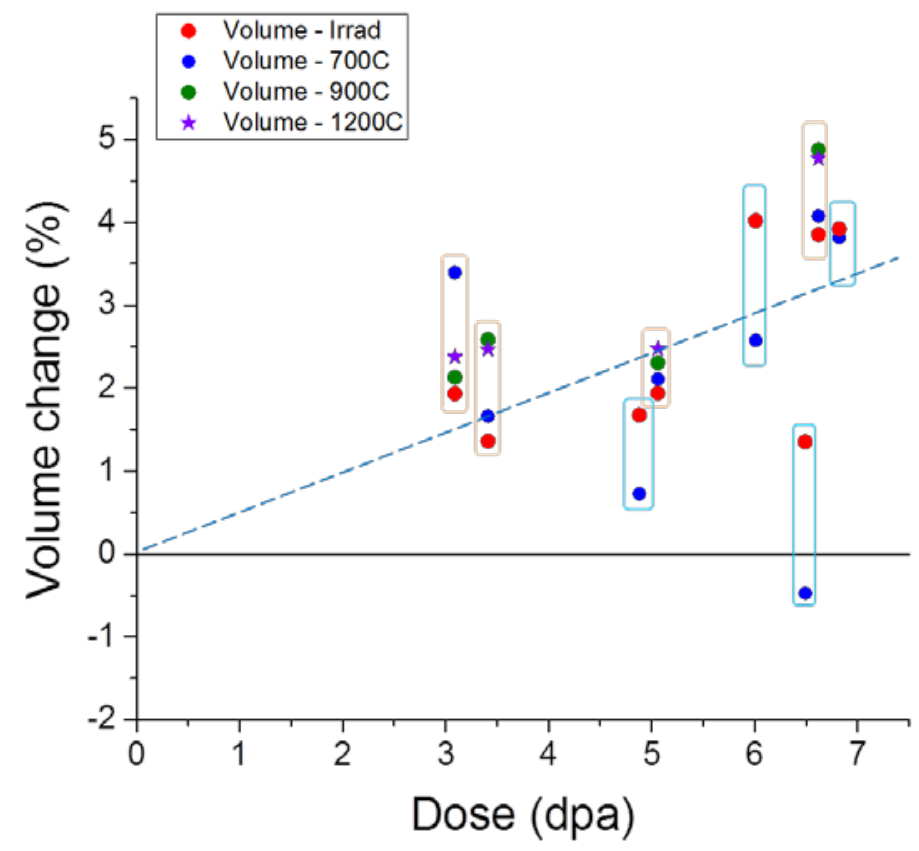

(c)

Figure 6. Effect of irradiation dose on bulk dimensions: (a) thickness (along graphite c-axis), (b) side dimension (along a-axis) and (c) volume. Note that orange (blue) boxes represent samples that have been annealed at three temperatures (one temperature). The lines were added to help guide the eye.

The crystal lattice parameters, $\mathrm{d}_{002}$ and $\mathrm{d}_{110}$, of the HOPG samples follow a similar trend-expansion of the c-axis $\left(d_{002}\right)$ and shrinkage of the a-axis $\left(d_{110}\right)$ after irradiation. The effect of dose on $d_{002}$ and $d_{110}$, after irradiation and after stepwise annealing, is shown in Figure 7. The changes in lattice parameters $\mathrm{d}_{002}$ and $\mathrm{d}_{110}$ for irradiated samples follow a familiar trend, with an apparent maximum (for $\mathrm{d}_{002}$ ) or a minimum (for $\mathrm{d}_{110}$ ) in the range of $5-7 \mathrm{dpa}$. Annealing at $700^{\circ} \mathrm{C}$ has the distinct effect of reducing the expansion of $\mathrm{d}_{002}$ (Figure 7a) while simultaneously increasing the shrinkage of $\mathrm{d}_{110}$ (Figure $7 \mathrm{~b}$ ). The higher the annealing temperatures, the larger is the drop in the initially expanded $d_{002}$ parameter, which 
tends to return close to the level of unirradiated samples (Figure 7a). A similar trend, although subtler, can be observed for the shrinkage of the $d_{110}$ lattice parameters (Figure $7 b$ ).

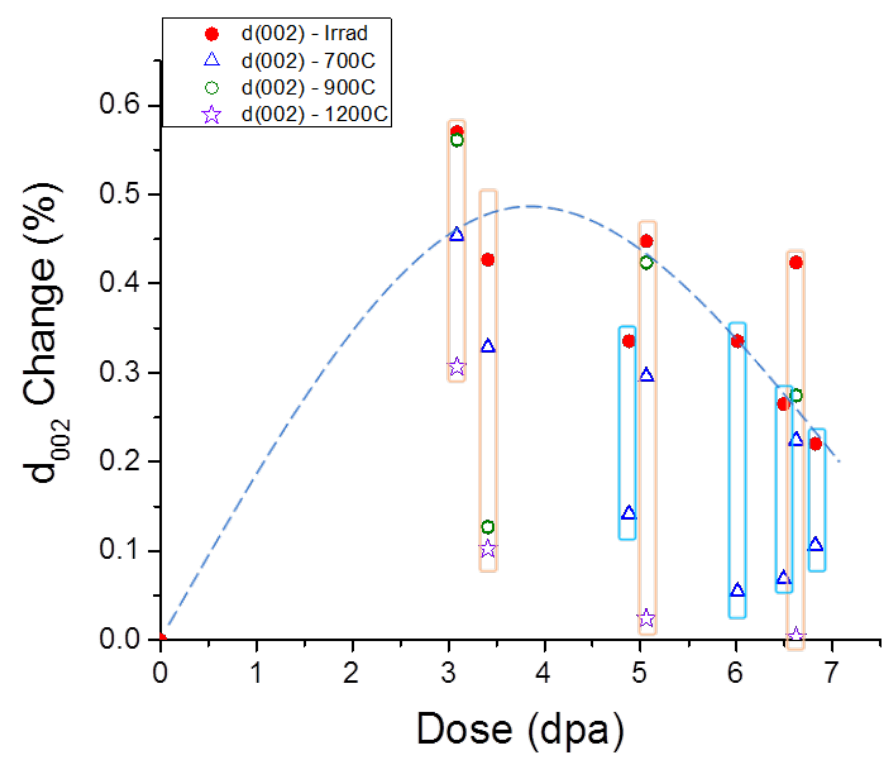

(a)

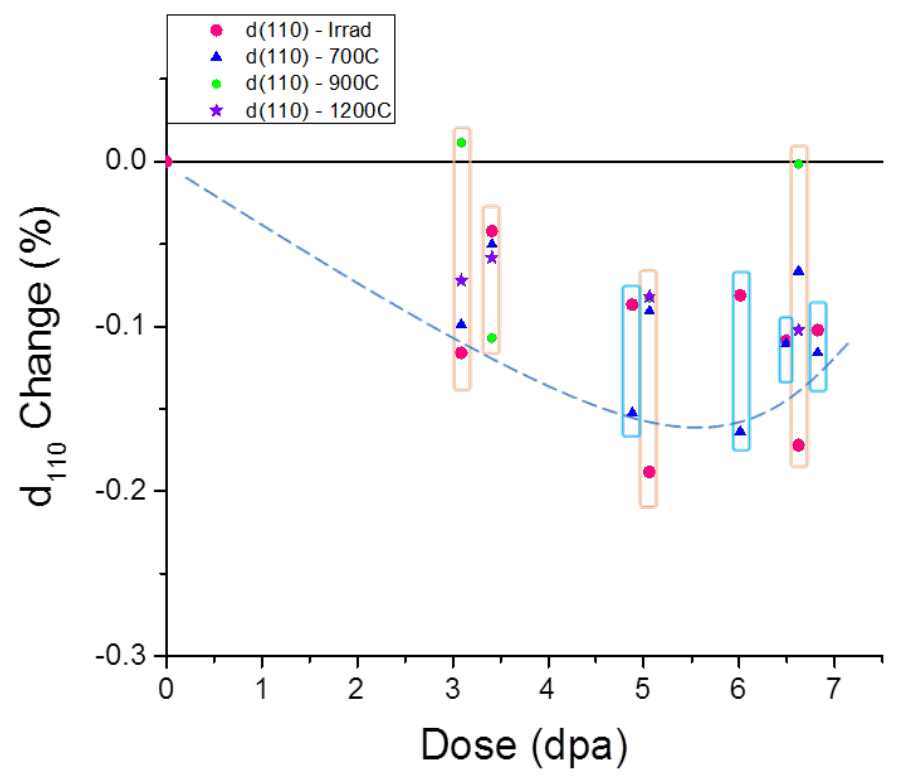

(b)

Figure 7. Effect of irradiation dose on lattice parameters (a) $d_{002}$ and (b) $d_{110}$. Note that orange (blue) boxes represent samples that have been annealed at three temperatures (one temperature). The trend lines were added to help guide the eye. 
Comparison of our results with those obtained on irradiated HOPG by Kelly and Brocklehurst ${ }^{7}$ in the 1970s and revisited later by Bonal et al. ${ }^{8}$ shows good agreement for the bulk dimensional changes due to neutron irradiation (Figure 8). Reports from Henson et al. ${ }^{9}$ (on nearly isotropic graphite) and Brocklehurst and Kelly ${ }^{10}$ (on HOPG) about irradiation-induced changes in crystal lattice dimensions also show good agreement with our results (Figure 9).

However, a significant difference is observed when comparing the magnitude of the bulk dimensional changes (Figure 6) with those of crystal lattice parameters: $\mathrm{d}_{002}$ expansion along the c-direction (Figure $7 a)$ and $d_{110}$ shrinkage along the a-direction (Figure 7b). Bulk dimensional changes are about one order of magnitude larger than the changes in the corresponding lattice parameters, $\mathrm{d}_{002}$ and $\mathrm{d}_{110}$. This suggests that bulk dimensional changes observed at the macroscale cannot be explained solely by expansion (along c-direction) or contraction (along a-direction) of crystal lattice parameters. In other words, the large dimensional variations at the macroscale (0.1-0.2 $\mathrm{mm}$ in this case) cannot be caused solely by lattice parameters variations at the nanoscale $\left(0.10-0.15 \AA\right.$ ). If, after accounting for the increase in $\mathrm{d}_{002}$, we were to attribute the dimensional expansion measured along c-axis to the growth of interstitial layers in the crystal lattice, as the bulk swelling along the c-axis is commonly explained, we would have to have a new interstitial layer every 10 to 20 layers.

The evident disconnect between these experimental facts is probably hidden in the mesoscale, the not-sowell-understood intermediate scale between nanoscale and macroscale. The results of SANS experiments reported below provide the elements of a possible explanation.

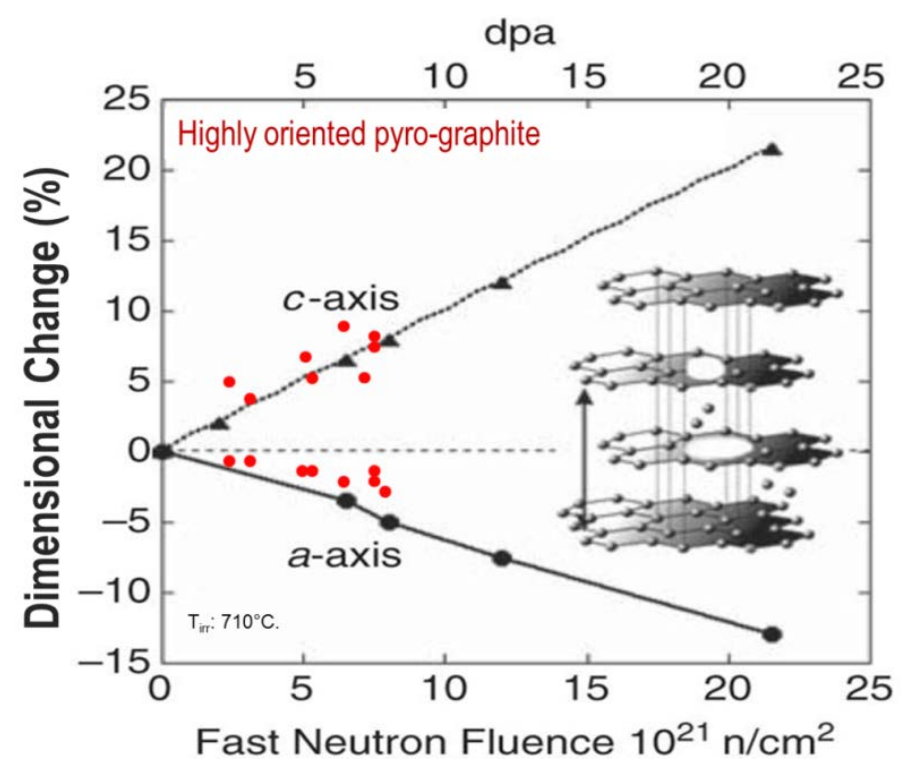

Figure 8. Comparison of results obtained here for dimensional changes of HOPG to those previously reported $^{8}$ (our results are represented by red circles, overlapped on the original figure).

\footnotetext{
${ }^{7}$ B.T. Kelly and J.E. Brocklehurst, “High dose fast neutron irradiation of highly oriented pyrolytic graphite,” Carbon 9 (1971) 783-789.

${ }^{8}$ J-P. Bonal, A. Kohyama, J. van de Laan, L. L. Snead, “Graphite, ceramics and ceramic composites for high-temperature nuclear power systems,” MRS Bulletin 34 (2009) 28-34.

${ }^{9}$ R.W. Henson, A.J. Perks, and J.H.W. Simmons, "Lattice parameters and dimensional changes in graphite irradiated between 300 and $1350^{\circ} \mathrm{C}, "$ Carbon 6 (1968) 789-806.

${ }^{10}$ J.E. Brocklehurst and B.T. Kelly, "The dimensional changes of highly oriented pyrolytic graphite irradiated with fast neutrons at $430{ }^{\circ} \mathrm{C}$ and $600{ }^{\circ} \mathrm{C}$,” Carbon 31 (1993) 179-183.
} 


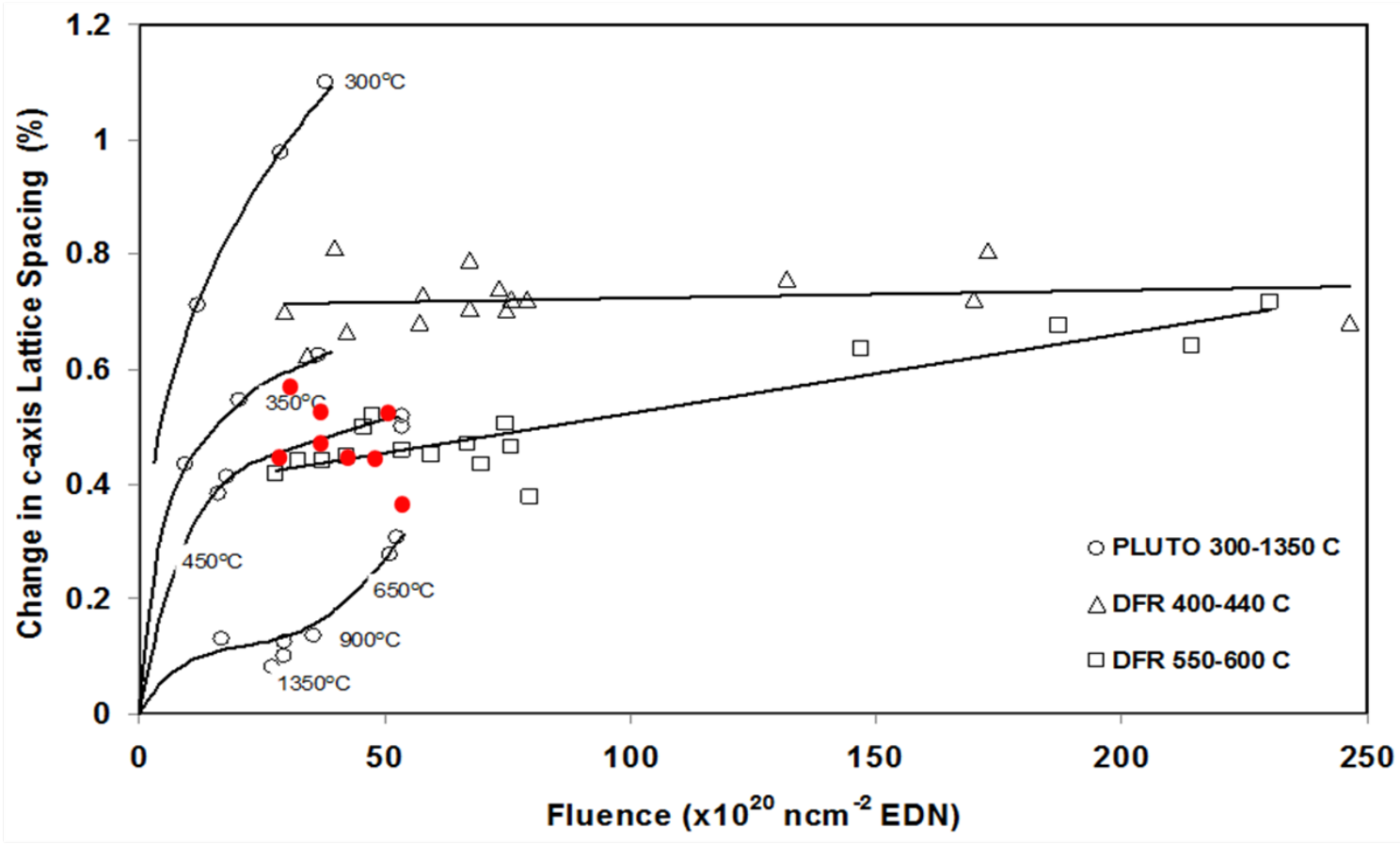

(a)

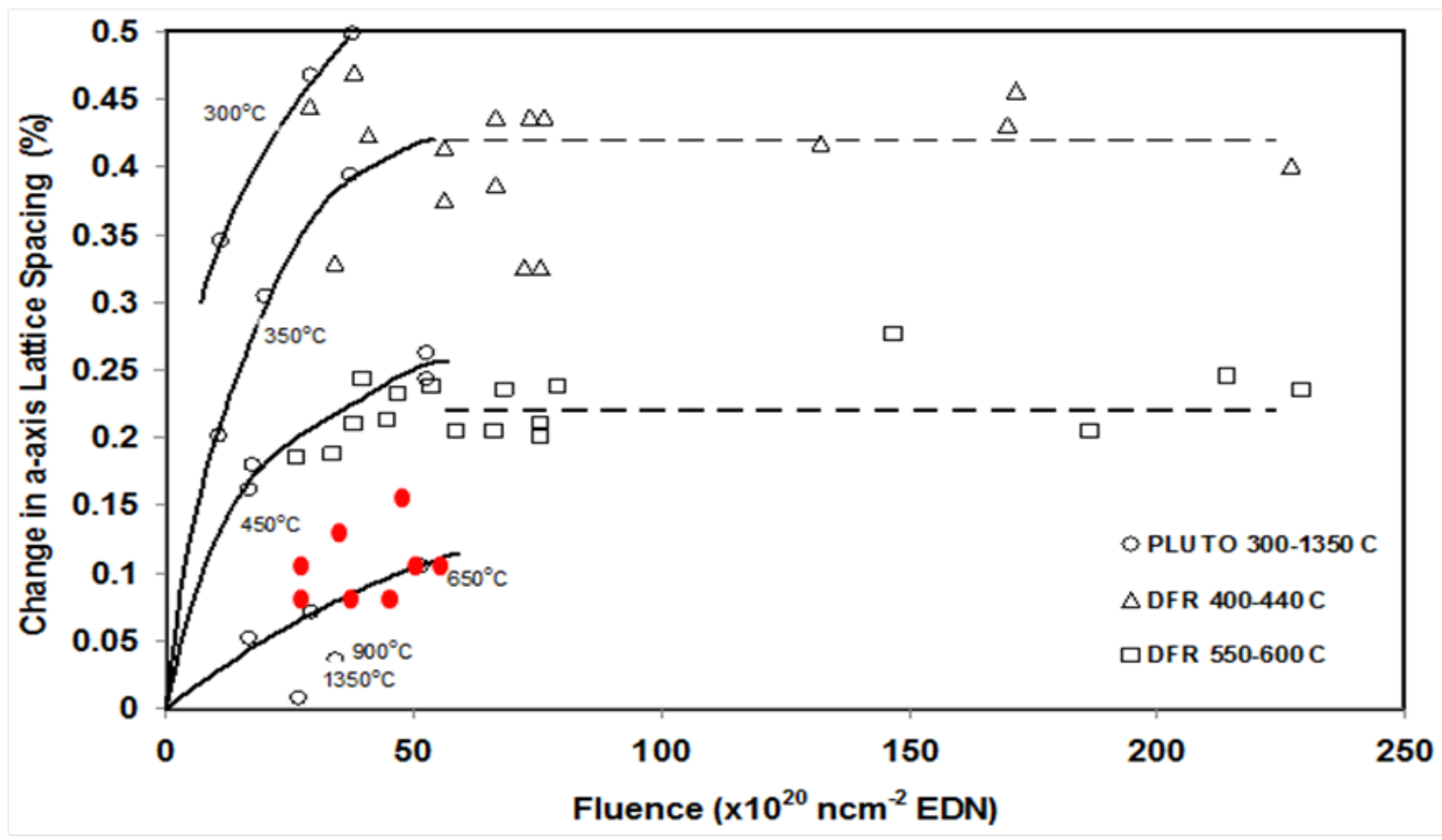

(b)

Figure 9. Comparison of results obtained for the HOPG from AGC-1 to those previously reported for a nearisotropic graphite (a) lattice parameter $\mathrm{d}_{002}$ and (b) lattice parameter $\mathrm{d}_{110}$ (our results are represented by red circles, overlapped on the original figures). ${ }^{9}$ 


\subsubsection{Small-Angle Neutron Scattering Results}

SANS studies were used to help understand the difference in the magnitude of the changes in crystalline parameters and bulk dimensional changes in HOPG samples after neutron irradiation. When SANS was introduced to this project, four of the eight HOPG samples had already been annealed to 700 and $900{ }^{\circ} \mathrm{C}$; therefore, SANS data for those four HOPG samples is only available after annealing at $900^{\circ} \mathrm{C}$. For the other four HOPG samples, SANS data was obtained only after irradiation and after thermal annealing at $700^{\circ} \mathrm{C}$. A summary of the samples and the available SANS data is listed in Table 5.

Table 5. List of HOPG samples and the various annealing treatments and SANS scans that have been applied to samples.

\begin{tabular}{|c|c|c|c|c|c|c|}
\hline & \multicolumn{2}{|l|}{} & $\begin{array}{c}\text { After } \\
\text { Irradiation }\end{array}$ & $\begin{array}{c}\mathbf{1}^{\text {st }} \text { Anneal } \\
\mathbf{7 0 0}^{\circ} \mathbf{C}\end{array}$ & $\begin{array}{c}\mathbf{2}^{\text {nd }} \text { Anneal } \\
\mathbf{9 0 0}^{\circ} \mathbf{C}\end{array}$ & $\begin{array}{c}3^{\text {rd }} \text { Anneal } \\
\mathbf{1 2 0 0}^{\circ} \mathbf{C}\end{array}$ \\
\hline Sample & $\begin{array}{c}\mathrm{T}_{\text {irr }} \\
\left({ }^{\circ} \mathrm{C}\right)\end{array}$ & $\begin{array}{c}\text { Dose } \\
(\mathrm{dpa})\end{array}$ & SANS scan & SANS scan & SANS scan & SANS scan \\
\hline $\begin{array}{c}\text { HOPG- } \\
\text { unirradiated }\end{array}$ & - & - & $\checkmark$ & - & - & \\
\hline CPB1 & 619 & 3.41 & n/a & n/a & $\checkmark$ & $\checkmark$ \\
\hline CPB21 & 678 & 5.06 & n/a & n/a & $\checkmark$ & $\checkmark$ \\
\hline CPB101 & 726 & 6.62 & n/a & n/a & $\checkmark$ & $\checkmark$ \\
\hline CPB161 & 511 & 3.09 & n/a & n/a & $\checkmark$ & $\checkmark$ \\
\hline CPB51 & 744 & 6.49 & $\checkmark$ & $\checkmark$ & n/a & n/a \\
\hline CPB71 & 751 & 6.82 & $\checkmark$ & $\checkmark$ & n/a & n/a \\
\hline CPB121 & 690 & 6.01 & $\checkmark$ & $\checkmark$ & n/a & n/a \\
\hline CPB141 & 622 & 4.88 & $\checkmark$ & $\checkmark$ & n/a & n/a \\
\hline
\end{tabular}

As described in Section 2.2.2, the structural information obtained by SANS comes from the plane normal to the direction of the $Q$ vector. Because of that, for complete analysis of the anisotropic HOPG specimens it was necessary to scan each specimen in two positions, namely, "flat" and "side". With specimens in the flat position, the neutron beam was normal to the basal planes, and the angular distribution of scattered neutron was isotropic, reflecting the regular atomic order of graphite basal planes. In this case the dependence of scattered intensity versus scattering angle, $I(Q)$, was obtained by radial integration (Figure 10). The result contains information along the a-axis of graphite (parallel to the basal plane). However, with the specimens in the side position, the neutron beam was parallel to the basal planes, and the distribution of scattered neutrons was highly anisotropic. To interpret these patterns based on the layered structured of graphite, the side patterns were integrated, covering a range of \pm 15 degrees, from the vertical V direction (parallel to graphite c-axis) and the horizontal $\mathrm{H}$ direction (parallel to graphite a-axis) axes. Integration along the two perpendicular directions resulted in two $I(Q)$ relationships representing scattering along the graphite c-axis (side V) and graphite a-axis (side H) (Figure 11). The former contains information on the inhomogeneities aligned with the direction of basal planes, and the latter contains information on the perpendicular direction to the basal planes.

The resultant scattering patterns for the unirradiated HOPG sample are shown in Figure 12. A typical Porod law behavior is observed for the flat and "side-horizontal" scans, which is characterized by linear variation of the double logarithmic plots $\log (I(Q))$ vs. $\log (Q)$ in the range of low $Q(Q<0.01)$. The slope of -3.37 indicates the presence of large ( $D>650 \AA$ ) scattering objects with rough interfaces. At large $Q$ angles the $\log (I(Q))$ vs. $\log (Q)$ slope becomes -1 for side-horizontal orientation. The slope for flat orientation even changes sign (increases) at $Q>0.1 \AA^{-1}$. The increase in scattering at large $Q$ may be 
caused by the occurrence of numerous inhomogeneities (e.g., nanopores) of sizes $<20 \AA$ or some sort of local fluctuations in atom densities, the resolution of which is limited by the $Q$-range achieved with the geometry of our tests. Similar features were reported from small-angle x-ray scattering (SAXS) and SANS studies of various types of coal ${ }^{11}$ and synthetic silicates. ${ }^{12}$ The slope of $\log (I(Q))$ vs. $\log (Q)$ plot for the "side-vertical" scan changes from -2 at $Q<0.005$ to -4 at $Q>0.03$. The slope of -2 at small $Q$ may indicate the presence of very thick $(>1200 \dot{A})$ disk-like scattering inhomogeneities resulting from misaligned packaging of individual graphitic crystallites in HOPG. It is known that HOPG is not a "macro-crystal” but a collection of flat crystallites with parallel arrangement and minimal angular misorientation. Multiple scattering on parallel basal planes at low $Q$ may also cause a similar slope change, as observed for anisotropic pyrolytic graphite with side orientation. ${ }^{13}$ Scattering by smaller size objects (larger $Q$ ) in the side-vertical direction shows the typical decay predicted by Porod law, $I(Q) \propto Q^{-4}$, which is an exact relationship at large $Q^{14}$ for systems with sharp boundaries between phases. ${ }^{15}$
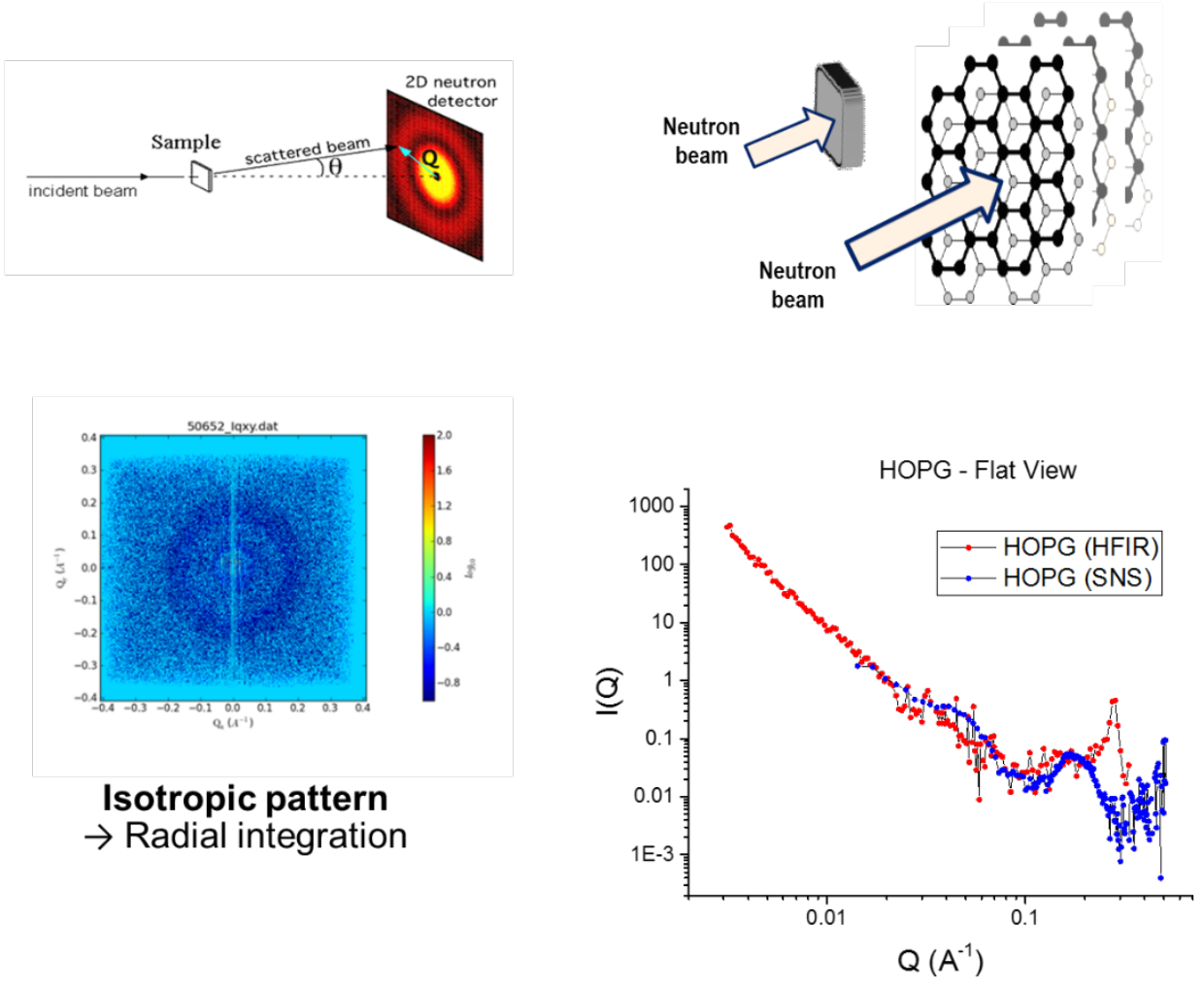

Figure 10. Schematic of flat SANS scan and corresponding analysis of the data.

\footnotetext{
${ }^{11}$ H. D. Bale, P. W. Schmidt, "Small-angle X-ray scattering investigation of submicroscopic porosity with fractal properties," Phys. Rev. Letters 53 (1984) 596-599.

12 K. D. Knudsen, J. O. Fussum, G. Helgesen, M. W. Haakestad, "Small -angle neutron scattering from a nano-layered synthetic silicate,” Physica B 352 (2004) 247-258.

${ }^{13}$ F. M. Hamzeh, R. H. Bragg, "Small-angle scattering of X-rays from groups of nonrandomly oriented ellipsoids of revolution of low concentration,” J Appl Phys 45 (1974) 3189-3195.

${ }^{14}$ C. G. Windsor, “An introduction to small-angle neutron scattering,” J Appl Cryst 21 (1988) 582-588.

${ }^{15}$ A. J. Jackson, Introduction to small angle neutron scattering and neutron reflectometry, NIST Center for Neutron Research, May 2009, https://www.ncnr.nist.gov/summerschool/ss10/pdf/SANS_NR_Intro.pdf
} 


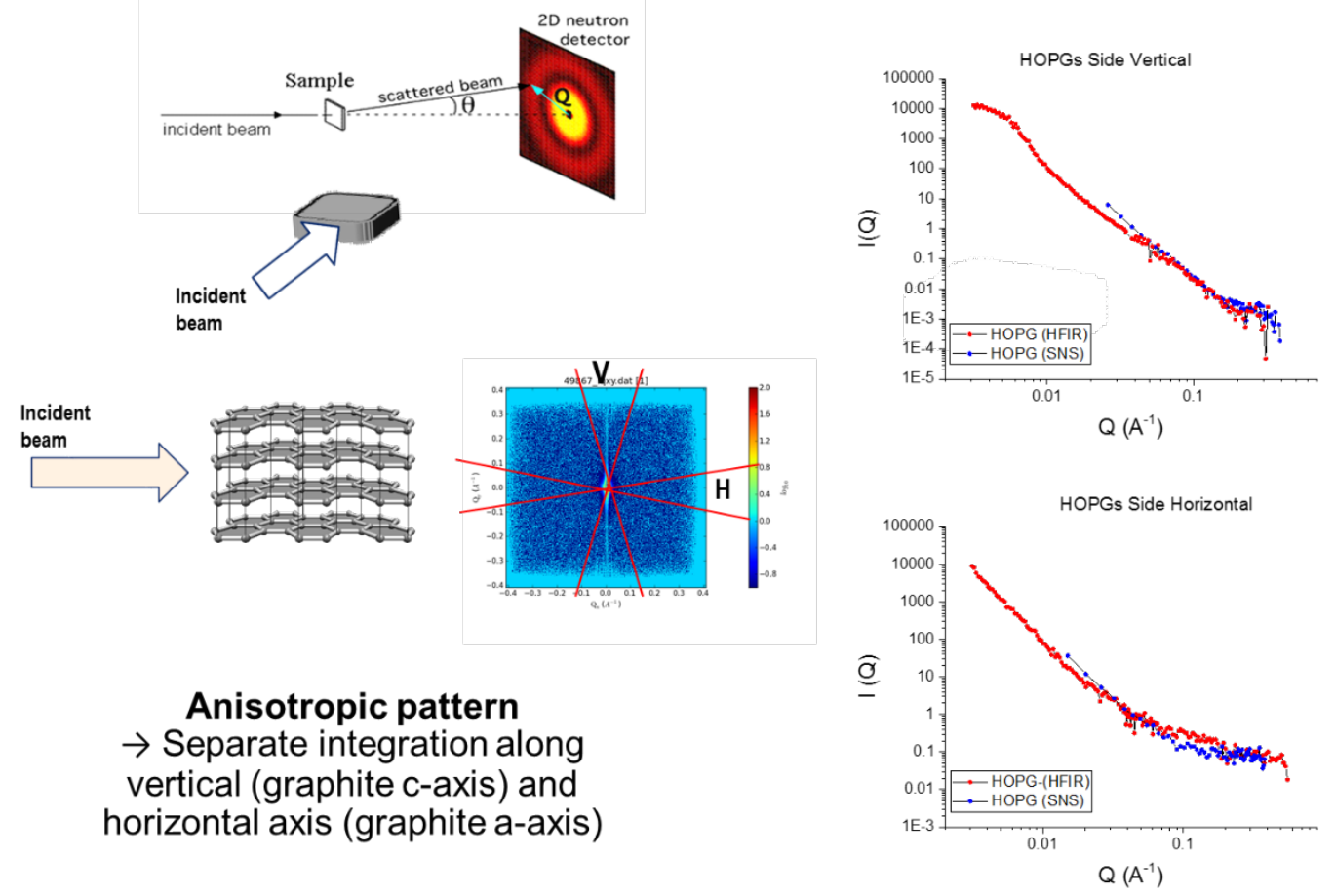

Figure 11. Schematic of side SANS scan and corresponding analysis of the data.

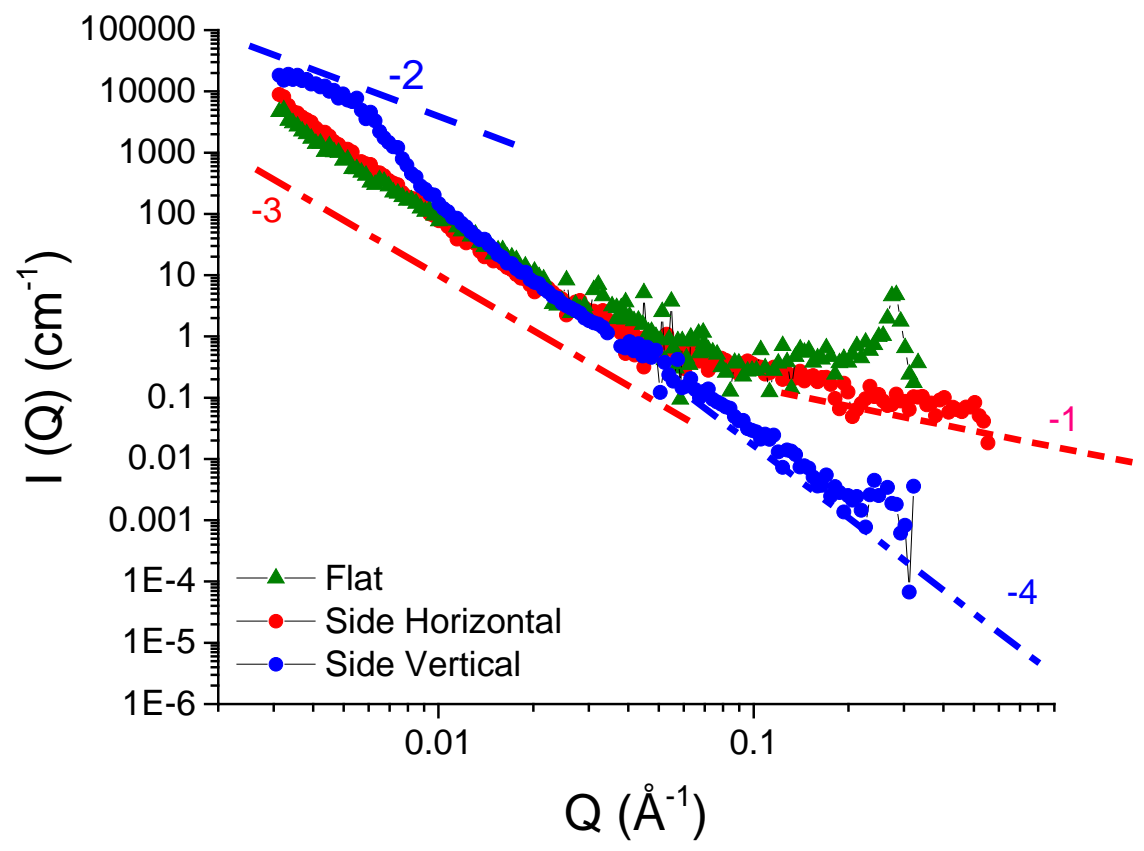

Figure 12. Reduced SANS patterns for unirradiated HOPG corresponding to flat and side (horizontal and vertical) positions. 
The SANS patterns for four HOPG samples, after irradiation and after annealing at $700{ }^{\circ} \mathrm{C}$, are shown in Figure 13 (scans along a-axis) and Figure 14 (scans along c-axis). These scans show new features in irradiated HOPG specimens which are not seen in $\log (I(Q))$ vs. $\log (Q)$ plots of unirradiated specimens.

Although the trends are similar for all specimens, there are small differences caused by variations in irradiation temperature and dose. Together, the scattering patterns suggest that large lens-shaped voids are present in all irradiated samples. When viewed on the flat and side-horizontal positions along the graphite a-axis (Figure 13), a large scattering intensification is observed for $0.01 \AA^{-1}<Q<\sim 0.3 \AA^{-1}$, which connects at $Q<0.01 \AA^{-1}$ with the scattering patterns of unirradiated specimens. It was found that the $Q$ values where enhanced scattering is observed correspond roughly to objects with sizes between $20-25 \AA$ and several hundred $\AA$. The angular and size ranges are roughly the same for flat and side-horizontal scans, suggesting that the same scatterers are detected in both positions. In contrast, scattering from the side-vertical position (Figure 14) along the graphite c-axis shows deviations only at large $Q$, corresponding to scattering characteristic lengths smaller than $100 \AA$. 

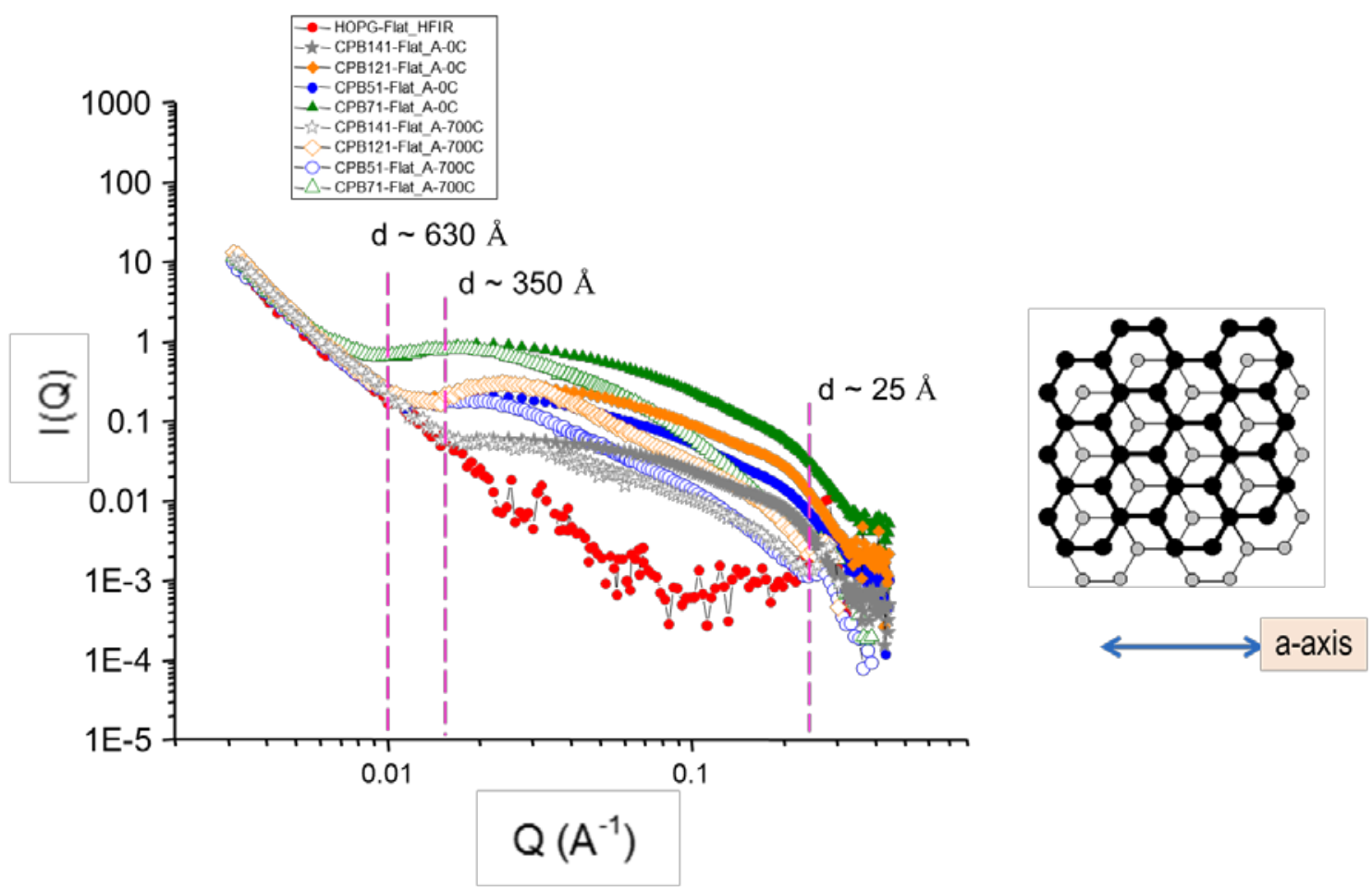

(a)
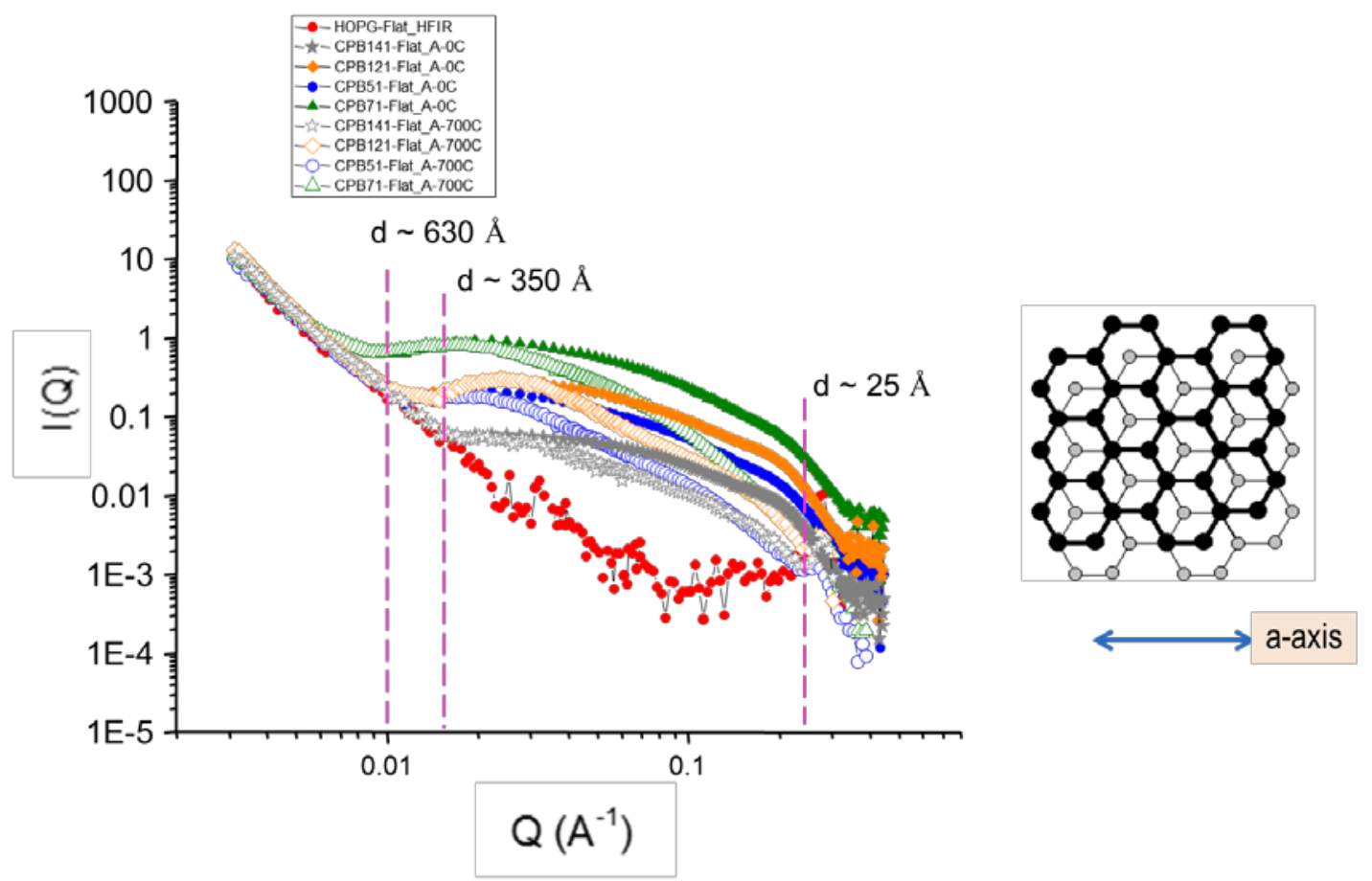

(b)

Figure 13. Reduced SANS patterns (a) flat view and (b) side-horizontal for four HOPG samples after irradiation (solid symbols) and after thermal annealing at $700^{\circ} \mathrm{C}$ (open symbols). 


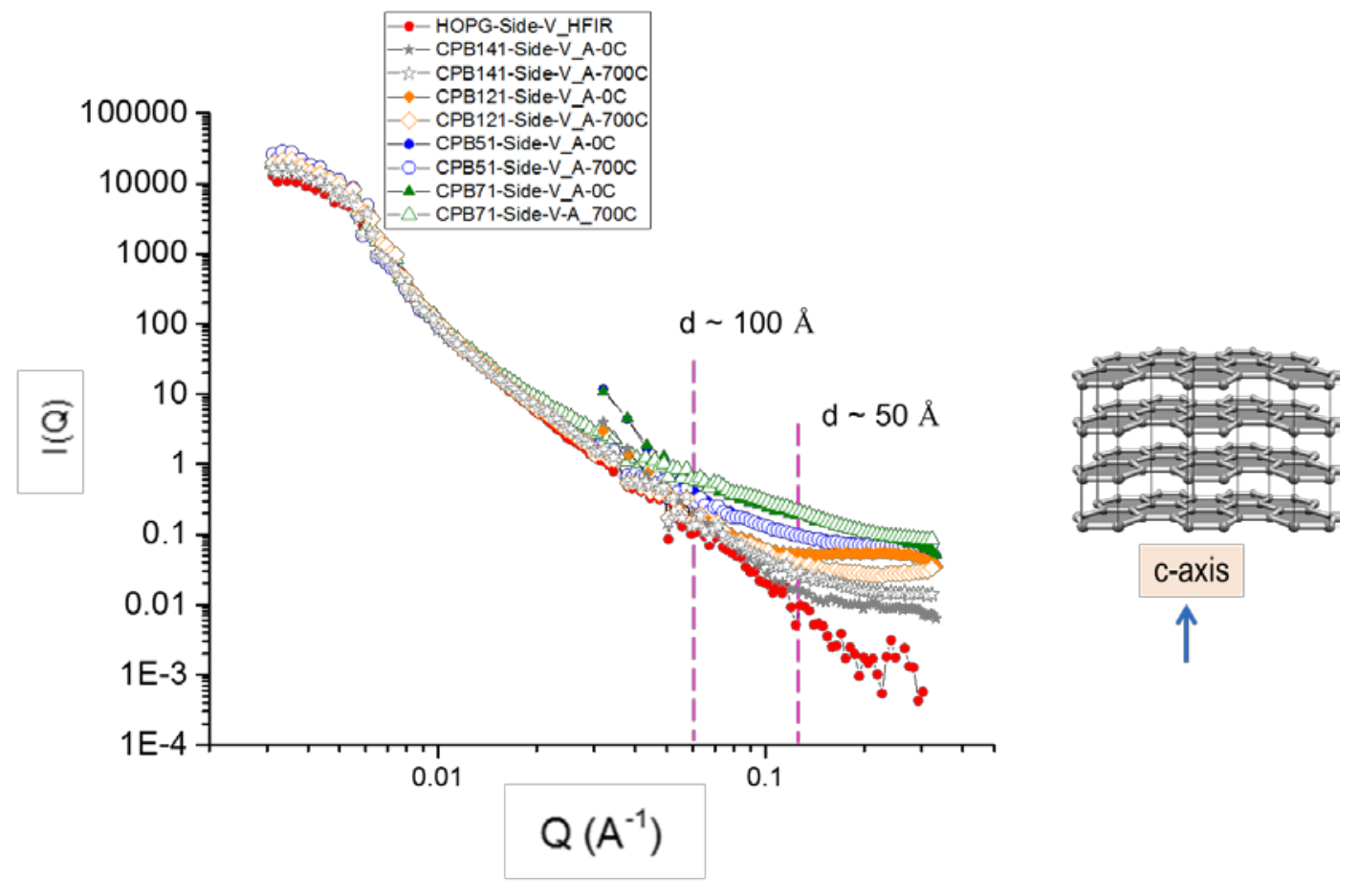

Figure 14. Reduced SANS patterns for side-vertical for four HOPG samples after irradiation (solid symbols) and after thermal anneal at $700^{\circ} \mathrm{C}$ (open symbols).

\subsubsection{Summary / Discussion}

The anisotropy of basal plane-oriented graphite was previously explored by SANS for flexible exfoliated graphite laminates (type Grafoil or Papyex). ${ }^{16,17,18}$ These anisotropic graphites were found to exhibit orientation-dependent neutron scattering patterns similar to those shown in Figure 10 and Figure 11 above. The SANS patterns of exfoliated graphite changed under external stress, indicating that applied pressures cause internal modifications of size and separation of scatterers (pores). However, the usual methods for characterization of porosity, such as Porod analysis at high $Q$ and Guinier and Debye analysis at low $Q$, did not provide credible results because the scattering pores in flexible graphite were either not isolated or outside the size range of application of these independent analysis models. ${ }^{16} \mathrm{~A}$ few other examples of analysis of SANS data for anisotropic structures were found in the literature. For example, the Guinier and Porod methods could not be used for a nanolayered silicate, and Debye analysis was used instead for characterization of direction-specific correlation lengths of several hundred $\AA .{ }^{19}$

All attempts to use similar procedures for quantitative analysis of SANS patterns of HOPG specimens faced significant difficulties: it was not possible to obtain linear plots for either of Guinier and Debye models, in their respective range of recommended $Q$ values. This is because most of these models are

\footnotetext{
${ }^{16}$ E. P. Gilbert, P. A. Reynolds, J. W. White, “Characterization of a basal-plane oriented graphite,” J Chem Soc Faraday Trans 94 (1998) 1861-1868.

${ }^{17}$ F. Balima, V. Pischedda, S. Le Floch, A. Brulet, P. Lindner, L. Duclaux, A. San-Miguel, “An in-situ small angle neutron scattering study of expanded graphite under a uniaxial stress,” Carbon 57 (2013) 460-469.

${ }^{18}$ F. Balima, S. Le Floch, A. San-Miguel, P. Lindner, A. Brulet, L. Duclaux, V. Pischedda, "Shear effects on expanded graphite under uniaxial pressure; An in-situ small angle neutron scattering study," Carbon 74 (2014) 54-62.

${ }^{19}$ K. D. Knudsen, J. O. Fossum, G. Helgesenm M. W. Haakestad, "Small-angle neutron scattering from a nano-layered synthetic silicate,” Physics B 352 (2004) 247-258.
} 
strictly applicable to systems with randomly distributed pores ${ }^{20}$ and therefore cannot be used for HOPG, which shows high structural anisotropy. Irradiation causes development of new features, which are highly dependent on orientation and therefore are not random. The new scattering objects have preferred orientation as they are constrained between parallel graphitic layers of covalently bonded carbon atoms. Given the lack of specific scattering models by anisotropic objects with preferred orientation and of variable size, the analysis of SANS results for irradiated HOPG will be limited to phenomenological aspects only.

When regarded in relation to each other, the direction-specific scattering intensity decay, $I(Q)$, in irradiated HOPG (Figure 13 and Figure 14) suggests the presence of lenticular inhomogeneities (microcracks) oriented parallel to basal planes and perpendicular to the c-axis. A schematic drawing is shown in Figure 15. These microcracks may have a lateral size (diameter) in the range of 25-630 $\AA$, as revealed by the new scattering patterns in flat and side-horizontal positions (Figure 13). Their thickness is much smaller, approximately between 50 and $100 \AA$, as suggested by scattering from side-vertical positions (Figure 14). The mechanism for development of these cracks is not yet understood. It is possible to envision that irradiation causes partial delamination of parallel plate-like crystallites adjoined on their basal planes crystallites in HOPG. Irradiation may cause buckling and separation of neighboring crystallites, leading to a net expansion on the c-axis direction. The net effect is the increase in thickness and volume as reported above (Figure 6). The presence of microcracks in unirradiated HOPG graphite was also reported by Wen et al., ${ }^{21}$ who used transmission electron microscopy and ion milling for sample preparation. In their study the cracks observed in unirradiated HOPG (SP-1 grade) had various lengths and widths and were separated by lamellae with thicknesses ranging from tens to hundreds of nanometers.
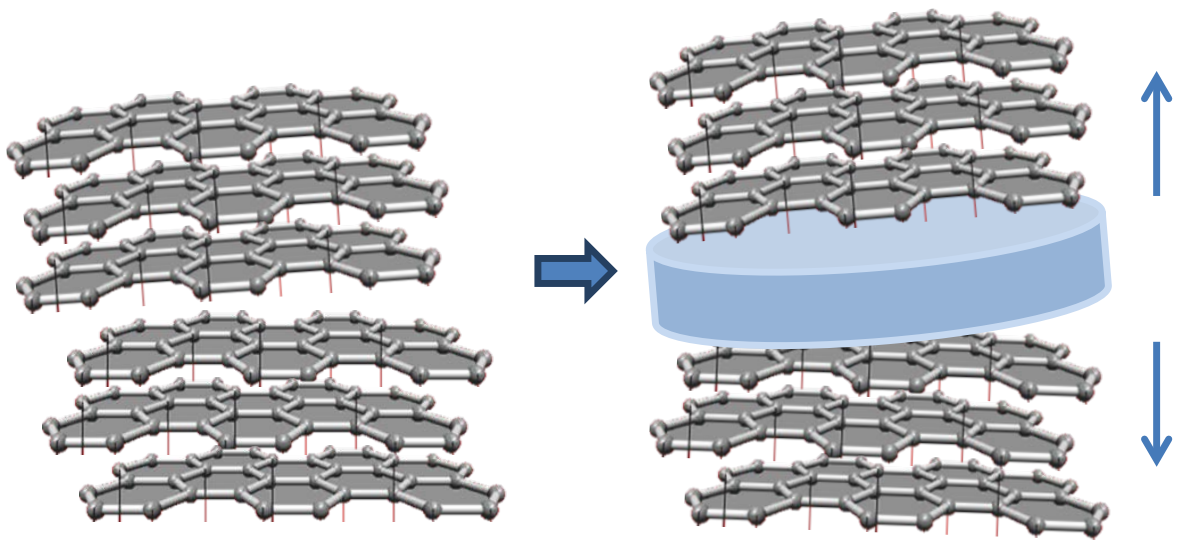

Figure 15. Schematic demonstration of a possible mechanisms leading to dimensional changes and microcrack development during irradiation: Irradiation may cause separation between slightly misaligned neighboring crystallites, increase of misalignment, and eventually void development between separated crystallites.

In summary, the results presented above demonstrate that irradiation of HOPG specimens causes expansion in the c-axis direction, shrinkage in the a-axis direction, and a net volume expansion. SANS results show the development of lenticular microcracks or mesopores aligned mostly parallel with the basal planes and with dimensions ranging from few nanometers thick up to several hundred nanometers in length or width. Although bulk dimensions and crystal lattice parameters vary in the same sense (expansion in c-axis direction and contraction in a-axis direction), there is a large difference between the

\footnotetext{
${ }^{20}$ P. Debye, H. R. Anderson, H. Brumberger, “Scattering by an inhomogeneous solid. II. The correlation function and its application,” J Appl Phys 28 (1957) 679-683.

${ }^{21}$ K. Wen, J. Marrow, B. Marsden, “Microcracks in nuclear graphite and highly oriented pyrolytic graphite (HOPG)”, J Nucl. Mater 381 (2008) 199-203.
} 
extents of these effects: bulk dimension variation is about 10 times greater than crystal parameter changes. The difference can partially be accounted for by the formation of new interstitial planes, roughing and buckling of basal planes followed by separation and misalignment between neighboring crystallite, and eventually generation and growth of new cracks and pores that contribute to expansion along the c-axis direction.

\subsection{MANUFACTURED GRAPHITE RESULTS}

\subsubsection{Dimensional Changes and XRD Results}

As mentioned earlier, samples from six grades of manufactured graphite were selected from the AGC-1 experiment (Table 1); however, complete characterization was carried out only on samples from three of the graphite grades (

Table 3). The results and discussion below are limited to those samples. A comprehensive report with the results from the PIE analysis was prepared by T.D. Burchell. ${ }^{22}$ Dimensional changes (length and diameter) versus irradiation dose of uncrept and crept specimens for the samples selected for this study are presented in Figure 16. Both length and diameter of all specimens suffered contraction, which became more pronounced with irradiation dose. In general, the length shrinkage was greater than the diameter contraction. The difference between crept and uncrept specimens can be immediately seen. The change in length is greater for crept samples than for the corresponding uncrept pairs. Diameter change, on the contrary, is smaller for crept samples than for uncrept samples.

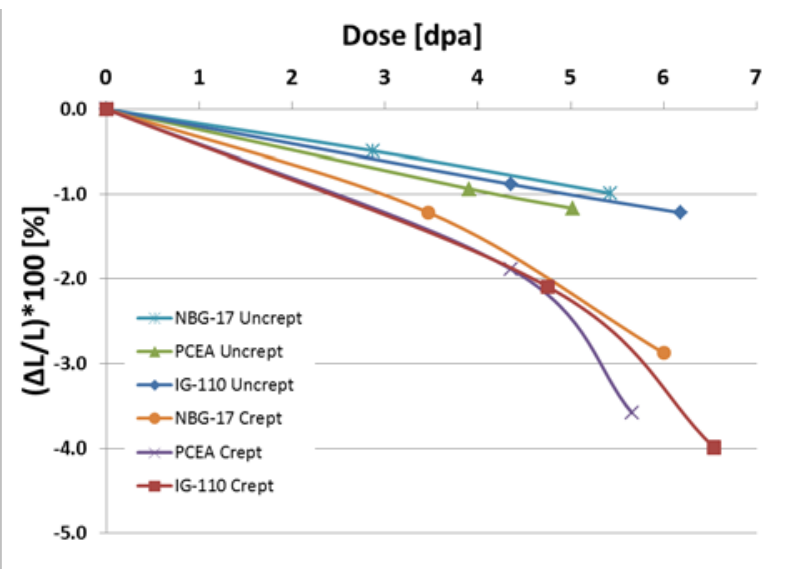

(a)

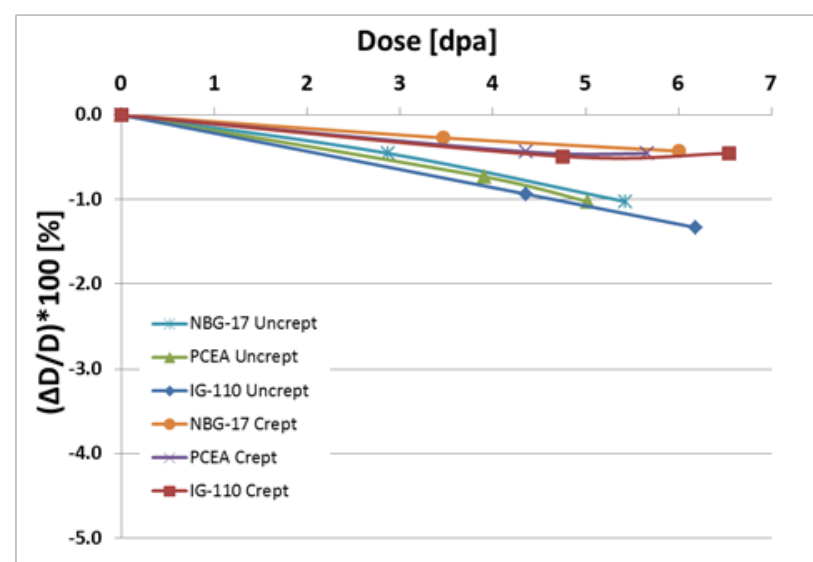

(b)

Figure 16. Dimensional changes along length and diameter for samples from graphite grades NBG-17, PCEA, IG-110.

The variation in crystalline parameters obtained from XRD studies for crept and uncrept samples is shown in Figure $17(\mathrm{a}, \mathrm{b})$. As expected, the $\mathrm{d}_{002}$ spacing increases with irradiation dose, showing an accumulation of defects in the crystal structure. However, the rate of increase is different between grades and also between crept and uncrept samples. For example, NBG-17 graphite shows a faster rate of $\mathrm{d}_{002}$ spacing increase when irradiated with no applied stress but a slower rate after irradiation under stress. It is interesting to compare the absolute values of $\mathrm{d}_{002}$ lattice spacing between irradiated polycrystalline graphite and HOPG (Figure 17c). All manufactured graphites have a larger $\mathrm{d}_{002}$ spacing before irradiation (3.367-3.370 $\AA$ ) than HOPG (3.350 $\AA$ ). This shows that the crystalline structure in manufactured graphite

${ }^{22}$ T Burchell, “AGC-1 specimen post irradiation data report”, ORNL/TM-2013/242 (September 2013) 
is less organized than in the HOPG material. Starting from a less-perfect structure, irradiation-induced defects in manufactured graphite have had lesser effects on the $\mathrm{d}_{002}$ parameter compared with HPOG. Reciprocally, irradiation defects in HOPG have had a greater effect on the $\mathrm{d}_{002}$ parameter, which expands more and becomes comparable with those of polycrystalline graphite.
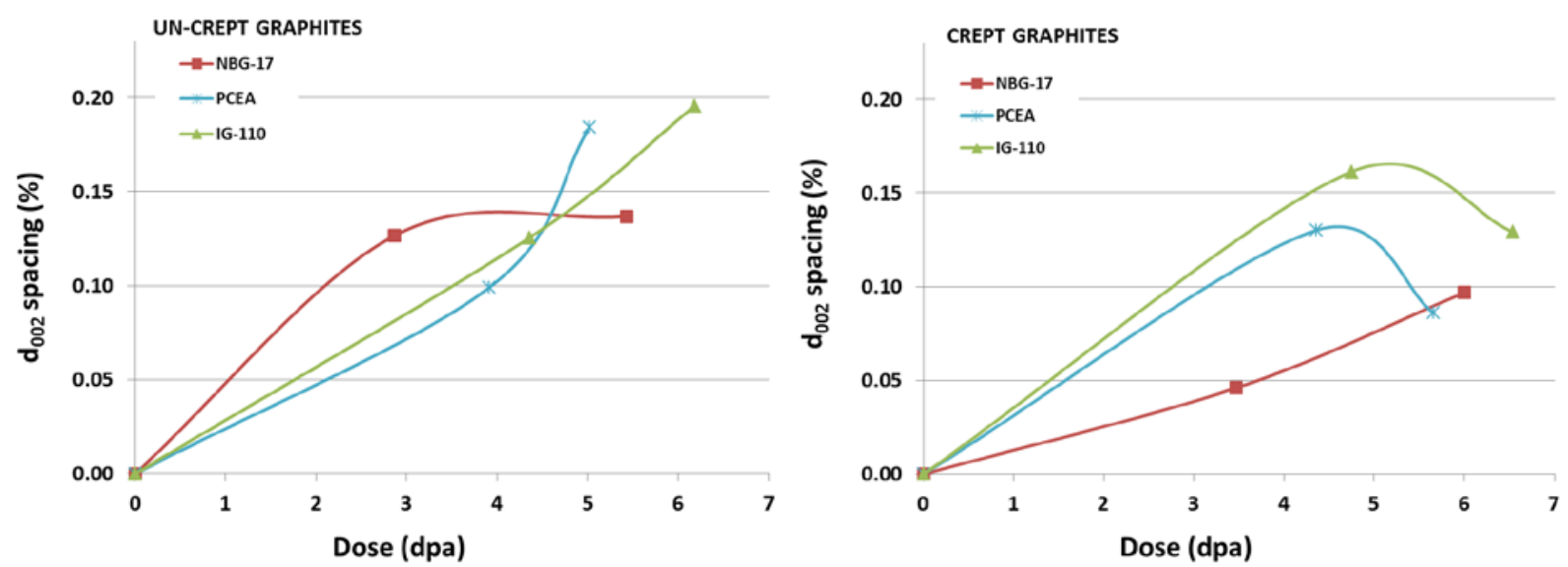

(a)

(b)

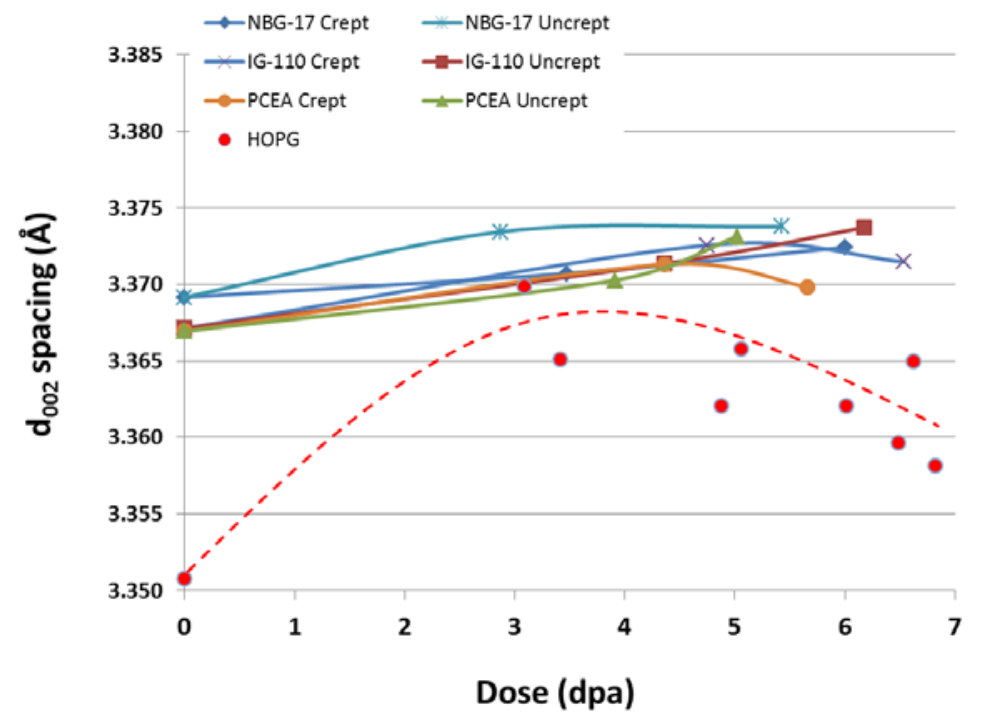

(c)

Figure 17. Changes in crystalline parameters d 002 for samples from graphite grades NBG-17, PCEA, IG-110: (a) uncrept samples, (b) crept samples, and (c) comparison of lattice spacing do02 between manufactured graphite and HOGP.

\subsubsection{SANS Results}

Figure 18a compares $Q$-dependence of scattering intensity $I(Q)$ for the three unirradiated graphite samples. In the range of small angle, $Q<0.2 \AA^{-1}$, the $\log (I(Q)$ vs. $\log (Q)$ plots vary linearly, according to the Porod law. The slope of linear segments is between -3 and -4 , as characteristic of rough, irregular interfaces. Neutron scattering at these small angles is caused by large voids, microcracks, and mesopores with dimensions between roughly 1400 and $30 \AA$. At $Q>0.2 \AA^{-1}$ the plots become flat. That can be 
interpreted either as an increased population of narrow pores (roughly below $30 \AA$ ) or may be caused by incoherent scattering from hydrogen atoms present in small concentrations on graphene edges.

Analysis of SANS data at large $Q$ can also be used to derive information on the pore size distribution of narrow pores $\left(<30 \AA\right.$ ) by fitting the scattering curves to a polydisperse spherical model. ${ }^{23}$ The model assumes that this narrow porosity can be represented by a collection of spherical pores with a certain distribution of sizes. The model, although not a perfect representation of the porosity in graphite, is still useful for getting some insight into the distribution of porosity, including open and closed pores. Figure $18 \mathrm{~b}$ shows the size distribution of narrow pores in unirradiated specimens, based on the spherical pore model. Narrow micropores ( $<20 \AA$ ) are present in all unirradiated graphite grades.

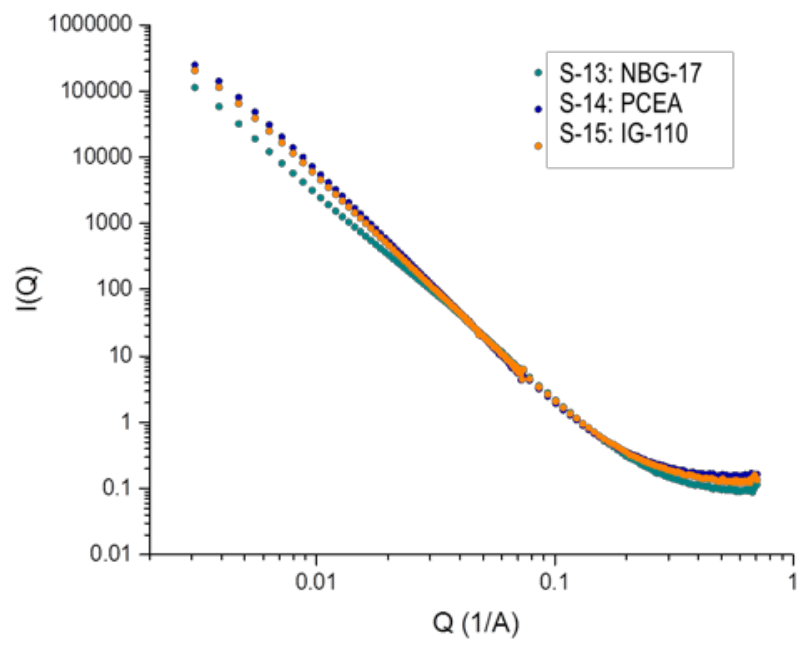

(a)

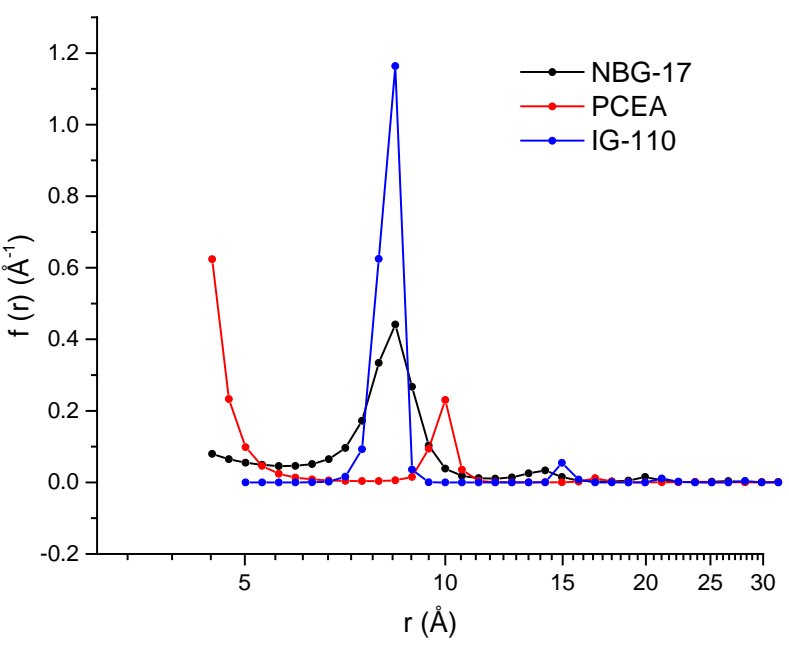

(b)

Figure 18. Unirradiated graphite samples: (a) SANS patterns and (b) corresponding pore size distribution obtained using the spherical pore model.

The SANS patterns obtained for all specimens (unirradiated and irradiated crept and uncrept) are shown in Figure 19. The double logarithmic plots are linear over a broad range of $Q$ that corresponds to scattering objects between (roughly) 30 and $2100 \AA$. Similar observations were previously made for nuclear graphite and were interpreted as a manifestation of the fractal structure of graphite internal pores and surfaces over a large range of sizes..$^{24,34,35,36,50}$ However, the slopes of these plots are not -4 , as predicted for the smooth character (independent of size) of the interfaces between scattering objects and the continuous solid matrix. On the contrary, the slopes (in absolute values) of double logarithmic plots vary in the order NBG-17 (3.16) < IG-110 (3.35) < PCEA (3.47). This order reflects differences between the graphites obtained from different precursors, as first observed by Martin and Caisley. ${ }^{25}$ Neutron scattering occurs at the filler/pores interface. NBG-17 has a pitch coke precursor, and its grains are rather spherical and less anisotropic, while IG-110 and PCEA are obtained from petroleum coke precursors and

\footnotetext{
${ }^{23}$ L. He, Y. B. Melnichenko, N. C. Gallego, C. I. Contescu, J. Guo, J. Bahadur, "Investigation of morphology and hydrogen adsorption capacity of disordered carbons,” Carbon 80 (2014) 82-90.

${ }^{24}$ Z. Zhou, W. G. Bouwman, H. Schut, S. Desert, J. Jestin, Z. Hartmann, C. Pappas, "From nanopores to macropores: Fractal morphology of graphite,” Carbon 96 (2016) 541-547.

${ }^{25}$ D. G. Martin, J. Caisley, "The influence of the coke source of nuclear graphites from neutron small-angle scattering experiments,” J Nucl Mater 67 (1977) 318-319.
} 
have mostly needle-like anisotropic filler grains. ${ }^{26}$ Moreover, for each graphite grade, the slope decreases (in absolute values) in the order unirradiated material > low dose > high dose. At similar levels of irradiation, the slopes of uncrept and crept samples are very similar to each other. This trend is illustrated in Figure 19 by the slope values shown for each $Q(I)$ plot. One single exception was found, where the PCEA sample irradiated at high dose in uncrept condition has a slope slightly higher than the unirradiated sample. The smaller the slope, the higher is the correlation between the properties of scattering objects (volume or area of separation surface). The decrease in slope with irradiation shows that internal pore surfaces become rougher and more irregular with an increase in dose. This is an expected result of irradiation-induced inhomogeneities in graphite structures, which was identified first by Martin and Caisley ${ }^{34}$ and reanalyzed recently by Mileeva, Ross, and King. ${ }^{36}$ Globally, the SANS data show that the distribution of inhomogeneities in unirradiated graphite depends on the specific precursor and then varies systematically as defects are introduced by irradiation.
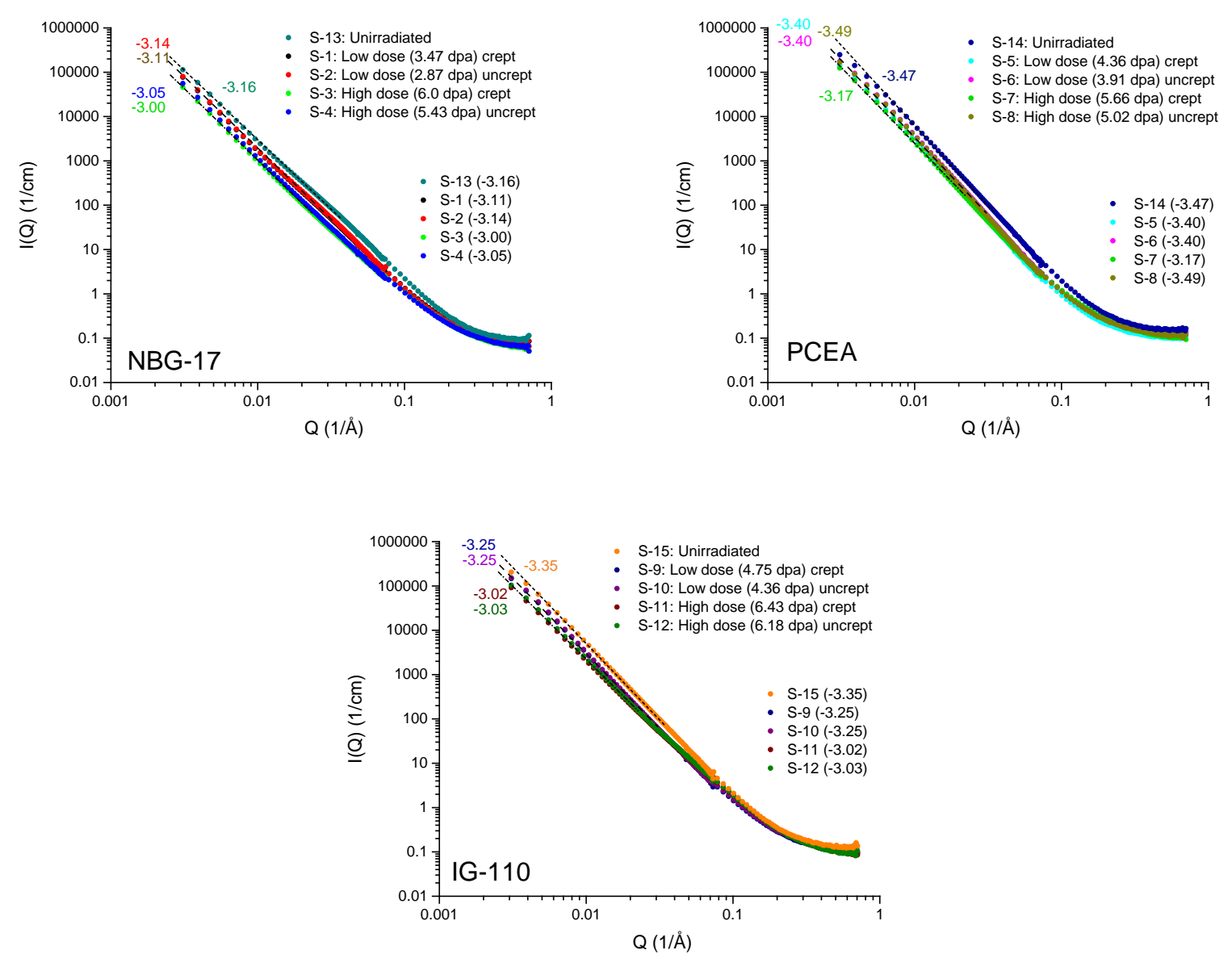

Figure 19. SANS patterns for NBG-17, PCEA, and IG-110 showing the effect of creep and irradiation dose. The general trend is a reduction in the slope at low $Q$ range with an increase in irradiation dose, while differences between crept and uncrept specimens are not as pronounced.

The SANS data were also used to calculate the pore size distribution of narrow pores using the spherical pore model. Although this model may not be ideal to represent pore geometry, models for more

\footnotetext{
${ }^{26}$ J. Kane, C. Karthik, D. P. Butt, W. E. Windes, R. Ubic, “Microstructural characterization and pore structure analysis of nuclear graphite,” J Nucl Mater 415 (2011) 189-197.
} 
complicated pore geometries are hardly available. The shape of graphite pores may also be represented as ellipsoids of revolution ${ }^{13}$ or disks, ${ }^{27}$ but even the spherical model offers an equivalent way, only simpler, for evaluation of pore distribution. The pore size distribution calculated based on the polydispersed spherical particles model ${ }^{28}$ is in fact a number density distribution. It was assumed that the scattering objects (pores, void, cracks) are isolated, not interfering with each other, and embedded in a homogeneous medium. ${ }^{23}$

Figure 20 compares the distribution of narrow pores $(<30 \AA)$ calculated at various doses (low/high) and creep conditions (crept/uncrept) for the three graphite grades. The changes introduced by irradiation and external load are different for each grade. Irradiation of uncrept graphites NBG-17 and IG-110 graphite causes shrinkage and gradual closure of sub-nanometer micropores. In contrast, irradiation of uncrept PCEA samples causes development of narrow size sub-nanometer micropores. Irradiation of crept NBG-17 specimens causes the micropores to shift to narrower sizes, but their volume does not drop much. A similar trend is observed for crept PCEA graphite samples; however, the volume of the narrower micropores increases significantly. Finally, irradiation of crept IG-110 graphite appears to cause the closure of most of the micropores.

${ }^{27}$ C-S. Tsao, M. Li, Y. Zhang, J. B. Leao, W-S. Chiang, T-Y. Chung, Y-R. Tzeng, M-S. Yu, S-H. Chen, "Probing the room temperature spatial distribution of hydrogen in nanoporous carbon by use of small-angle neutron scattering," J Phys Chem C 114 (2010) 19895-19900.

${ }^{28}$ A. P. Radinski, M. Mastalerz, A. L. Hinde, A. Hainbuchner, H. Rauch, M. Baron, "Application of SAXS and SANS in evaluation of porosity, pore size distribution and surface area of coal,” Int J Coal Geol 59 (2004) 245-271. 

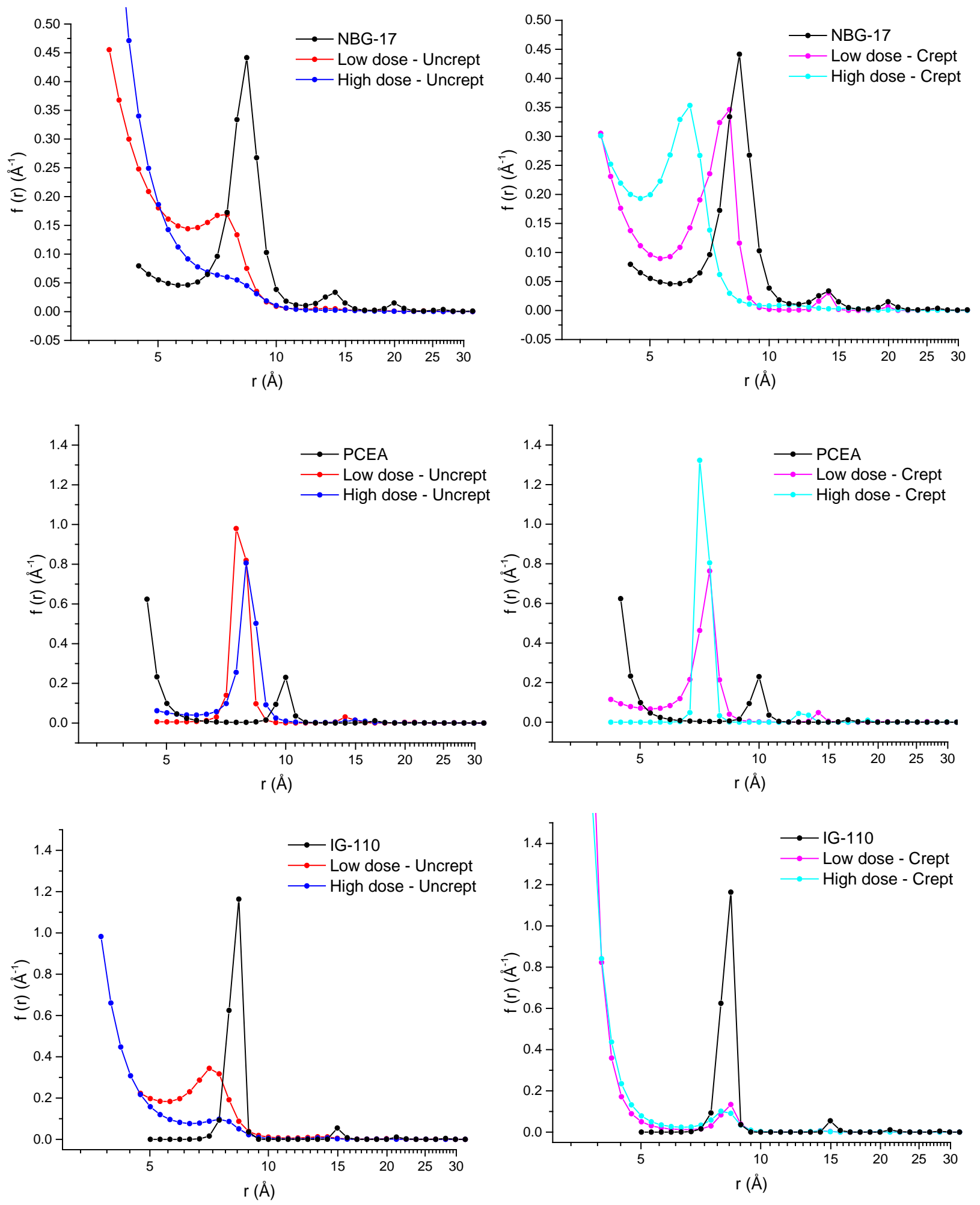

Figure 20. Pore size distribution obtained from SANS patterns for irradiated samples of NBG-17, PCEA, and IG-110 graphite. 


\subsubsection{Summary / Discussion}

The results obtained by fitting scattering data to preselected pore models are dependent on the selected pore geometry. However, investigation of this narrow (sub-nanometer) porosity is worth doing as it may shed unexpected light on the nanostructures in irradiated graphite. Moreover, these results can be compared with information from gas adsorption. Only a few preliminary results from gas adsorption on nuclear graphite were available at the time of this writing. However, it was already shown that comparing pore size distribution from SANS and gas adsorption provided useful information on the structure of porous carbons. ${ }^{23,44}$

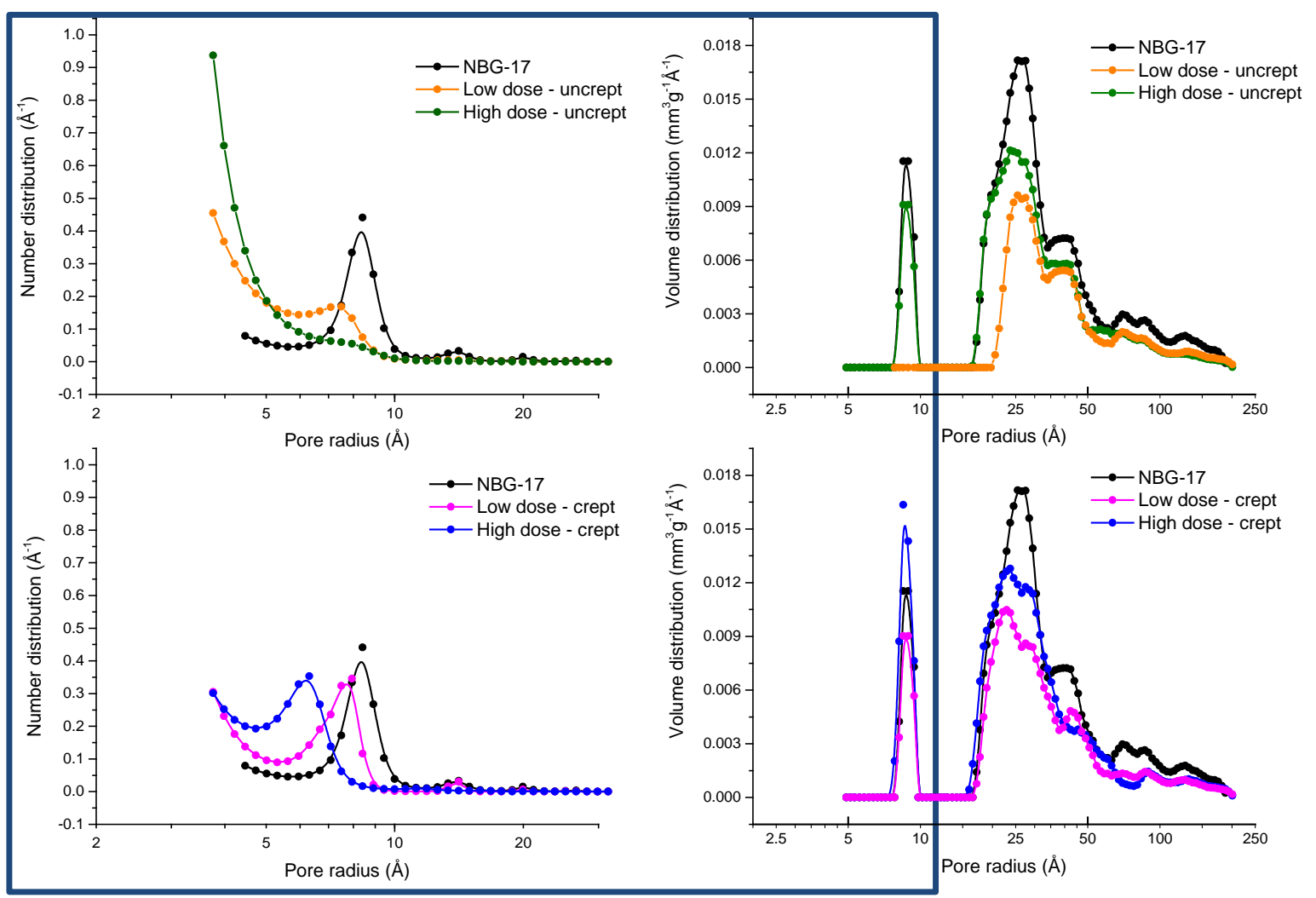

Figure 21. Comparison of pore size distribution obtained from two methods of porosity analysis: SANS (left panel) and nitrogen adsorption (right panel) applied to the same NBG-17 specimens.

Figure 21 shows SANS results for pore size distribution of NBG-17 graphite and data for the same samples measured by nitrogen adsorption at $77 \mathrm{~K}$. The porosity analysis of gas adsorption data was done using the density functional theory method for quenched surfaces (QS-DFT) available for Quantachrome commercial instruments. SANS and gas adsorption methods complement each other, but there is also a difference: while SANS "sees" all pores, open and closed, gas adsorption "sees" only open pores. The plots in Figure 21 show that micropores $(<10 \AA$ radius) detected by SANS were also measured by gas adsorption. Gas adsorption also found a group of mesopores (up to $250 \AA$ radius) outside the range of porosity analyzed by the SANS spherical model. Low-dose irradiation causes partial closure of these mesopores and partial reopening at high doses. Nevertheless, SANS provides better resolution for micropores below $10 \AA$.

This research should continue to investigate better models for calculating pore size distribution from SANS data, based on more realistic pore geometry assumptions. Also, significant progress has been 
recently made at ORNL in gas adsorption characterization of mesoporosity development in superfine grain graphite irradiated at doses beyond the turnaround point of dimensional variations. ${ }^{29}$ It appears that the volume expansion that starts after turnaround is accompanied by a significant increase in mesoporosity in the range of 50-200 $\AA$. These results can be further corroborated with similar reports based on electron microscopy. ${ }^{21,30,31,32}$

${ }^{29}$ C. I. Contescu, A. Campbell, N. C. Gallego, K. Takizawa, Y. Katoh, “Mesopore development in irradiated graphite,” International Nuclear Graphite Specialists Meeting (INGSM) 2017, Baltimore, MD, September 17-21, 2107.

${ }^{30}$ C. Karthik, J. Kane, D. P. Butt, W. E. Windes, R. Ubic, “In situ transmission electron microscopy of electron-beam induced damage process in nuclear grade graphite:”, J Nucl Mater 412 (2011) 321-326.

${ }^{31}$ J. A. Hinks, A. N. Jones, A. Theodosiou, J. A. van der Berg, S. E. Donnelly, J Phys, Conf. Ser 371 (2012) 012046.

${ }^{32}$ H. M. Freeman, A. N. Jones, M. B. Ward, F. S. Hage, N. Tzelepi, Q. M. Ramasse, A. J. Scott, R. M. D. Brydson, “On the nature of cracks and voids in nuclear graphite', Carbon 103 (2016) 45-55. 


\section{CONCLUSIONS}

There is a notable difference between the irradiation response of HOPG and polycrystalline graphites. SANS shows the development of large internal voids of lenticular shape, nested parallel with basal planes. These inhomogeneities most probably vary in size and can reach $\sim 600 \AA$ in diameter and up to $100 \AA$ in thickness. It is not clear where these defects are located and what the mechanism of their development is. They may be internal to HOPG crystallites and formed by delamination and exfoliation, or they may be external to crystallites and formed by the buckling and separation of interfaces between different crystallites. On the other hand, irradiation of polycrystalline graphite causes systematic changes in the fractal material's properties, namely by increasing the roughness of the phase-separation interfaces. SANS and gas adsorption show changes in the density and size of narrow micropores (SANS) and mesopores (gas adsorption), but it is not clear how these changes occur.

Based on all the evidence provided, it seems that expansion of $d_{002}$ and shrinkage of $d_{001}$ lattice constants are remotely responsible for the dimensional changes of both HOPG and polycrystalline graphite macroscale specimens. Expansion in the thickness of HOPG specimens along c-axis may well be correlated with the growth of lenticular microcracks revealed by SANS. Assuming that the average thickness of lenticular microcracks is $50 \AA$ (based on Figure 14), a rough estimate shows that these void defects would occur on average every 150 graphene layers in order to explain the maximum expansion observed for HOPG. This scenario is more realistic than the estimates for polycrystalline graphite based on the development of interstitial layers and considering observed lattice constant variations. Calculations show that a new interstitial layer would have to appear every 10-20 graphene layers to explain the growth along the c-axis, which is not very probable.

Unfortunately, analysis of SANS data could not identify the development of new pores of hundred $\AA$ sizes in irradiated polycrystalline graphite. The slopes of $I(Q)$ vs. Q plots decrease continuously with irradiation dose in all graphites examined by SANS. The change in slopes can be interpreted either as an

increase in surface roughness or the effect of changes in the number density of large versus small pores. If irradiation produces fewer large size pores (visible at low $Q$ ) and more narrow size pores (visible at small $Q$ ), a change of slope would also be observed. In this scenario, the multiplication of small size pores (below $300 \AA$ ) might possibly be detected by gas adsorption measurements. On the other hand, according to current views, diminution of the number of large size pores is expected after irradiation at doses before the volume turnaround point. These pores are perhaps outside the range of SANS analysis, but they might be observed at very small angles in USANS spectrometers. 



\section{APPENDIX}

The purpose of this appendix is to provide a brief description of small-angle neutron scattering (SANS) and to illustrate the main data analysis methods that can be used for extracting information from SANS experiments.

In the SANS spectrometer, a specimen is bombarded with a neutron beam of controlled wavelength. The neutrons scattered in a small solid angle along all directions are collected and analyzed as a function of the angular direction between the incident neutron beam and the scattered beam. The total scattered intensity is composed of several parts, as shown below ${ }^{33}$ :

$$
I_{T}=I_{C}+I_{I C}+I_{M C}+I_{B G} \text {. }
$$

Here $I_{C}$ is the coherent scattered intensity, which contains information on the structure and lattice; the incoherent scattering $I_{I C}$ occurs from nuclear spins scattering; the multiple scattering $I_{M C}$ and the background scattering $I_{B G}$ signals are weak perturbations that should be eliminated or compensated in the data reduction step. The most important information is contained in the elastic part of coherent scattering. If scattering occurs without energy loss, the scattering vector $Q=\mathrm{k}_{\text {init }}-\mathrm{k}_{\text {final }}$, defined as the momentum difference between the impinging neutrons and scattered neutrons, contains structural information on atoms' arrangement. On the other hand, the magnitude of the scattering vector for elastic scattering is

$$
|\mathbf{Q}|=Q=\frac{4 \pi(\sin \theta)}{\lambda}=2 \Delta k \sin \theta,
$$

where

$$
\Delta k=\left|\mathbf{k}_{\text {init }}\right|=\left|\mathbf{k}_{\text {final }}\right| .
$$

The scalar magnitude of $Q$ depends on the scattering angle $2 \theta$ and the wavelength of the neutron beam $\lambda$. For elastic scattering, the scattering intensity $I(Q)$ represents the coherent neutron cross section per unit volume in units of $\mathrm{cm}^{-1}$ and is given by

$$
I(Q)=4 k_{n}^{2} \varphi(1-\varphi) V F(Q)
$$

where $\varphi$ is the volume fraction of pores in the sample (total porosity), $V$ is the volume of the sample illuminated by the neutron beam, and $F(Q)$ is a form factor of pores. In the above equation, the parameter $k_{n}{ }^{2}$ is the neutron contrast between the scattering length density (SLD) of the carbon matrix ( $\rho^{*} \mathrm{C}$ ) and the SLD of the fluid filling the pores $\left(\rho^{*}\right)$. Both these parameters are functions of atomic scattering lengths $(b)$ and atomic masses $(M)$ of constituent elements. The Bragg equation $\lambda=2 D \sin \theta$ provides an approximate relationship between the scattering vector $Q$ and the characteristic length $D$ of structural inhomogeneities in the carbon matrix:

$$
D \cong 2 \pi / Q
$$

This relationship will be used to estimate the linear pore width of scattering pores in graphite. The rule of thumb is that the larger the $Q$ in the reciprocal space (expressed in $\AA^{-1}$ ) the smaller is the size $D$ of scattering objects in the real space (measured in $\AA$ ). Since the wavelength of cold source neutrons is about

\footnotetext{
${ }^{33}$ T. Egami, S. J. L. Billinge, “Underneath the Bragg peaks: Structural analysis of complex materials,” Pergamon (Publ.), 2003, Chapter 2.
} 
3-5 $\AA<\lambda<20 \AA$, from Eqs. (A-2) and (A-4) it follows that spatial structures with sizes

$1 \mathrm{~nm}<D<300 \mathrm{~nm}$ correspond approximately to $Q$ values in the range $0.02 \AA^{-1}<Q<6 \AA^{-1}$. The magnitude of $Q$ is limited by the physical size of the spectrometers (the sample-to-detector distance). Measurements at small scattering angles (for large scattering objects) are possible with large spectrometers, having lengths of several meters.

SANS measurements can uniquely provide multiscale information, from sub-nanometer to sub-micron scales. SANS is widely used to characterize porous materials, and more recently it has also been applied to nuclear graphite ${ }^{34,35,36}$ and porous carbons. ${ }^{37,38,39,40,41,42}$ By exploring a much larger sample volume than all microscopy techniques, the information obtained from SANS is more statistically significant for the bulk of materials. This is significantly different from all microscopy techniques which explore miniscule spots at the sample's surface.

The structural information collected by SANS comes from objects residing in the plane perpendicular to the direction of $Q$ vector. In two-phase materials SANS provides information on the structure of the phase separation interface. For dilute systems of random particles, the average particle size can be calculated from the radius of gyration $R_{g}$ obtained from plots of Guinier equation in the low- $Q$ limit. This approximation is valid only for $Q R_{g} \ll 1$.

$$
\ln (I(Q))=\ln (I(0))-\frac{R_{g}^{2}}{3} Q^{2}
$$

On the other hand, according to Porod's law applicable in the high- $Q$ limit, $I(Q)$ trends asymptotically to a constant value (Porod's invariant, $Q^{*}$ ) which reflects the specific surface (volume-normalized) of the sample. The law is valid at $Q>>1 / D$, where $D$ is the size of the scattering object.

$$
\left(\frac{\pi}{Q *}\right) \times \lim _{Q \rightarrow \infty}\left(I(Q) \times Q^{4}\right)=\frac{S}{V} .
$$

If the scattering objects have a random shape and size distribution, scattering can be characterized by an exponential correlation function. In the low- $Q$ range the correlation length $\xi$ can be obtained from the Debye equation:

\footnotetext{
${ }^{34}$ D. G. Martin, J. Caisley, "Some studies of the effect of irradiation on the neutron small angle scattering from graphite," Carbon 15 (1977) 251-255.

${ }^{35}$ D. G. Martin, J. Caisley, "Some studies of the effect of thermal and radiolytic oxidation on the neutron small angle scattering from nuclear graphites,” Carbon 16 (1978) 199-203.

${ }^{36}$ Z. Mileeva, D. K. Ross, S. M. King, “A study of the porosity of nuclear graphite using small-angle neutron scattering,” Carbon 64 (2013) 20-26.

${ }^{37}$ P. G. Hall, S. A. Muller, R. T. Williams, "Sorptive properties and small angle neutron scattering from porous carbons,” Carbon 27 (1989) 103-111.

${ }^{38}$ J. M. Callo, O. J. Hall, M. Antxustegi, “Carbon porosity characterization via small angle neutron scattering,” Colloids and Surfaces A 187-188 (2001) 219-232.

${ }^{39}$ N. Cohaut, A. Thery, J. M. Guet, J. N. Rouzaud, L. Kocon, “The porous network in carbon aerogels investigated by small angle neutron scattering,” Carbon 45 (2007) 1185-1192.

${ }^{40}$ L. He, S. M. Chathoth, Y. B. Melnichenko, V. Presser, J. McDonough, Y. Gogotsi, "Small-angle neutron scattering characterization of the structure of nanoporous carbons for energy-related applications,” Microporous Mesoporous Materials 149 (2012) 46-54.

${ }^{41}$ T. X. Nguyen, S. K. Bhatia, "Characterization of accessible and inaccessible pores in microporous carbons by a combination of adsorption and small angle neutron scattering,” Carbon 50 (2012) 3045-3054.

${ }^{42}$ R. Zhang, S. Liu, J. Bahadur, D. Elsworth, Y. Melnichenko, L. He, Y. Wang, "Estimation and modeling of coal pore accessibility using small angle neutron scattering,” Fuel 161 (2015) 323-332.
} 


$$
I(Q)=\frac{k}{\left(1+Q^{2} \xi^{2}\right)^{2}}
$$

where $k$ is a constant. Debye analysis was used for extracting correlation lengths of ellipsoid-shaped pores with random orientation.

More information can be obtained from SANS regarding the properties of the interface of scattering objects in two-phase materials. Here is where the notion of fractality must be introduced.

All small-angle scattering observations on isotropic porous carbon, ${ }^{43,44}$ anisotropic pyrolytic graphite, ${ }^{45}$ (near)isotropic nuclear graphite, ${ }^{46,47,48,49,50}$ and HOPG (this study) demonstrate that scattering intensity varies with the scattering vector (or angle) according to the general power law:

$$
I(Q) \propto Q^{d-6},
$$

where $d$ can be interpreted as a fractal dimension of the system. For two-phase systems the fractal dimension $d$ is simply a number which shows how the magnitude of the phase separation surface depends on selection of the unit surface used for measuring the area. While the separation surface may appear locally smooth and details-free when it is compared against a very small surface area unit (e.g., on atomic or crystallite size range), the same surface may show roughness in its wholeness when it is analyzed over a much larger scale. In this definition the fractal dimension varies between $d=2$ for a perfectly smooth surface and $d=3$ for an extremely rough surface, convoluted so much that it fills a 3D volume. The former case corresponds to the Porod law $\left(I(Q) \propto Q^{-4}\right)$ for surfaces that appear locally smooth (large $Q$ numbers, sub-nanometer scale details). Most two-phase materials, however, show rough separation surfaces for which $2<d<3$. That leads to power law decay of $I(Q)$ with a fractional exponent between 3 and 4:

$$
I(Q) \propto Q^{-s} ; \quad 3<s<4 .
$$

Indeed, the $s$ values from the SANS patterns in Figure 19 vary between 3.0 and 3.5. Using these values, it is possible, in principle, to calculate the fractal area of each specimen ${ }^{16}$ and to compare with the BET areas determined from nitrogen adsorption isotherms. Indeed, the area of fractal surfaces depends on the yardstick (or length scale) used for probing the surface:

$$
S(r)=S_{x} r^{2-d}
$$

\footnotetext{
${ }^{43}$ N. C. Gallego, L. He, D. Saha, C. I. Contescu, Y. B. Melnichenko, "Hydrogen confinement in carbon nanopores: Extreme densification at ambient temperature,” J Am Chem Soc 133 (2011) 13794-13797.

44 J. Bahadur, Y. B. Melnichenko, L He, C. I. Contescu, N. C. Gallego, J. R. Carmichael, "SANS investigation of CO2 adsorption in microporous carbon," Carbon 95 (2015) 565-544.

${ }^{45}$ R. H. Bragg, M. L. Hammond, J. C. Robinson, “Small-angle scattering by pyrolytic graphite,” Nature 200 (1963) 555-557.

${ }^{46}$ D. G. Martin, J. Caisley, "Some studies on the effect of irradiation on the neutron small angle scattering from graphite," Carbon 15 (1977) 251-255.

${ }^{47}$ D. G. Martin, J. Caisley, "Some studies of the effect of thermal and radiolytic oxidation on the neutron small angle scattering from nuclear graphites,” Carbon 16 (1978) 199-203.

48 Z. Zhou, Q. G. Bouwman, H. Schut, S. Desert, J. Jestin, S. Hartmann, C. Pappas, "From nanopores to macropores: Fractal morphology of graphite," Carbon 96 (2016) 541-547.

49 Z. Mileeva, D. K. Ross, S. M. King, “A study of the porosity of nuclear graphite using small-angle neutron scattering,” Carbon 64 (2013) 20-26.

${ }^{50}$ E. Hoinkis, A. J. Allen, "A study of porosity and interfacial area in original and oxidized POCO graphite AXM-5Q1 using small angle neutron scattering,” Carbon 29 (1991) 81-91.
} 
where $r=2.27 \dot{\mathrm{A}}$ is the radius of nitrogen molecules and $S_{x}$ is the surface area for an assembly of scattering objects with fractal surfaces, ${ }^{51}$ and has dimensions of $\mathrm{m}^{\mathrm{d}} \mathrm{g}^{-1}$.

${ }^{51}$ A J Hurd, D W Schaeffer, A M Glines, “SANS study of sintering rough surfaces’ J Appl Cryst 21 (1988) 864-869 
